\title{
Integrated automation for optimal demand management in commercial buildings considering occupant comfort
}

CORRESPONDING AUTHOR:

FAKEHA SEHAR

EMAIL ADDRESS: SEHAF0@VT.EDU

CONTACT NO.: +1 (571) 241-2846

FAX NO.: +1 (571) 858-3315 


\section{Integrated automation for optimal demand management in commercial buildings considering occupant comfort}

Fakeha Sehar (sehaf0@vt.edu) ${ }^{\text {a }}$, Manisa Pipattanasomporn ${ }^{\mathrm{a}}$ and Saifur Rahman ${ }^{\mathrm{a}}$

${ }^{\mathrm{a}}$ Virginia Tech-Advanced Research Institute, Arlington, VA, 22203 USA

Abstract - Implementing demand response (DR) in commercial buildings can play a major role in reducing building's peak load. This improves the efficiency of electricity grids and mitigates expensive peak demand/energy charges for buildings. Due to the lack of Energy Management Systems, small and medium-sized commercial buildings have not historically played much role as a DR resource. This paper presents an integrated control of major loads in commercial buildings, i.e., cooling, lighting and plug loads that can maintain occupant environmental preferences. Each zone's space temperature set points are optimally adjusted to maintain thermal comfort. Lighting levels, with and without daylight availability, are tightly controlled to maintain desired illuminance levels. Unlike other studies, this research contributes to improvement in functionalities of EnergyPlus by incorporating a 1-minute resolution data set at the individual plug load level. The research evaluates total building performance including interdependencies between lighting, plug load, HVAC and control systems interacting in a realistic manner, both among themselves and with building occupants. In this paper, a method to determine the DR potential of a building, i.e., the amount of electrical demand $(\mathrm{kW})$ by load type that can be shifted or shed, is discussed.

Keywords

Demand Response; Smart Buildings; Occupant Comfort; Energy Management System; Smart Grid

Abbreviations

ASHRAE : American Society of Heating, Refrigerating, and Air-Conditioning Engineers;

CBECS : Commercial Building Energy Consumption Survey;

DF : Daylight factor;

DOE : Department of Energy;

DR : Demand Response;

DX : Direct Expansion;

EMS : Energy Management System;

Erl : EnergyPlus Runtime Language;

HVAC : Heating, Ventilation and Air-Conditioning; 
IESNA : Illuminating Engineering Society of North America;

PMV : Predicted Mean Vote;

PNNL : Pacific Northwest National Laboratory;

VAV : Variable air volume

\section{Introduction}

Implementing Demand Response (DR) programs in buildings provides opportunities for peak demand reduction (FERC, 2011; Kreuder \& Spataru, 2015; Wang, Biviji, \& Wang, 2011) and in doing so help reduce energy costs (Smith \& Brown, 2015) and increase renewable energy share (Gils, 2014). DR provides control of end users' electrical demand in response to grid signals (Yan, Xue, Wang, \& Cui, 2015). DR changes the time pattern and magnitude of utility's load and results in increasing the efficiency and use of system assets (Gelazanskas \& Gamage, 2014). The use of Energy Management System (EMS) is not widespread in small and medium-sized commercial buildings $\left(<9,290 \mathrm{~m}^{2}\right)$ (Goldstein \& Bloom, 2014; Katipamula et al., 2012). These buildings represent $94 \%$ of all commercial buildings, and consume $44 \%$ of the total energy of the commercial buildings in the U.S. according to the Commercial Building Energy Consumption Survey (CBECS) 2012 (EIA, 2012). Due to the lack of controls significant amount of energy consumed in these buildings is wasted (Katipamula et al., 2012).

Among different types of commercial buildings, office buildings consume more than $17 \%$ of the total energy used by the commercial buildings sector in U.S. (EIA, 2010). Major end-use loads in office buildings are lighting, cooling and office equipment, which account for about 39\%, 14\% and 15\% of electricity consumption respectively (EIA, 2008). There are studies that discuss possible DR strategies for controlling Heating, Ventilation and Air-Conditioning (HVAC), lighting and plug loads. These studies are summarized below:

HVAC-based DR strategies: Usually commercial buildings are overcooled (Derrible \& Reeder, 2015). (Page, Kiliccote, Dudley, \& Piette, 2011) demonstrated and showed limited DR savings due to non-optimized DR strategies and lack of customer awareness towards DR. They concluded that there is a need to improve DR performance for small and medium-sized commercial buildings and measurement of load reductions from end-uses. Different HVAC-based DR strategies include global temperature adjustment of zones and systemic adjustments to the air distribution and cooling systems (Motegi, Piette, Watson, Kiliccote, \& $\mathrm{Xu}, 2007$ ). (Watson, Kiliccote, Motegi, \& Piette, 2006) and (Motegi et al., 2007) field-tested HVAC-based DR strategies, and indicated global temperature adjustment of zones best achieves DR goal. (Tzivanidis, Antonopoulos, \& Gioti, 2011) correlated cooling energy usage with thermostat operation to better understand relationship between energy consumption and thermal comfort. (Yanga, Yana, \& Lam, 2014) provided a summary of some case studies analyzing energy consumption with changes in summer set point temperatures. (Plat, Ward, \& Wall, 2011) showed that applying global set point changes during peak hours 
results in poor distribution of HVAC capacity across zones and an uneven distribution of occupant satisfaction across the building. (Al-Mulla \& ElSherbini, 2014) reported demand savings associated with closure of air-conditioning units or rise in cooling set points for different types of buildings. (Sehar, Pipattanasomporn, \& Rahman, 2016) showed that although global temperature adjustment was able to achieve more peak load savings but is unable to maintain thermal comfort in all zones across a building.

Lighting DR strategies: Control of electric lighting adapting to changes in occupancy and daylight while maintaining illumination comfort can reduce building energy consumption. (Dubois \& Blomsterberg, 2011; Galasiu, Atif, \& MacDonald, 2004; Newsham, Aries, Mancini, \& Faye, 2008; Park, Ryu, Choi, \& Kim, 2014; Shen, Hu, \& Patel, 2014) discussed different types of lighting control strategies for peak load reduction including harvesting daylight, continuous dimming and on/off strategies implemented in commercial buildings. (Al-Mulla et al., 2013) showed peak demand savings of 0.23MW achieved in a group of eight buildings with de-lamping for a typical summer day. (Shen et al., 2014) demonstrated poor light performance for lighting control integrated with occupancy and HVAC in cooling dominated spaces. (Galasiu \& Veitch, 2007) provided an overview of occupant behavior from studies examining occupant preferred light levels in office buildings with natural daylight available and light controls. (Boyce et al., 2006; Moore, Carter, \& Slater, 2002; Veitch \& Newsham, 2002) indicated that occupants prefer illuminance levels lower than recommended values. (Ashley \& Reynolds, 1994; Gentile, Laike, \& Dubois, 2014; Love, 1998; Moore, Carter, \& Slater, 2003) indicated occupants electric lighting use is seldom affected by daylight availability, higher levels of electric light use have been observed with higher external illuminance (Begemann, Beld, \& Tenner, 1997; Gentile et al., 2014). In order to get benefits from daylight control, automatic controls either providing automatic lights switching or photoelectric dimming are needed to avoid the risk of more energy usage.

Plug loads DR strategies: Plug loads are defined as electricity-consuming loads which are different than building end-use loads including HVAC and lighting. Office buildings are usually unoccupied $66 \%$ to $75 \%$ of the hours in a year and occupants are usually seated at their desk for about 10\% of the year (Lobato, Sheppy, Brackney, Pless, \& Torcellini, 2012; Metzger, Cutler, \& Sheppy, 2012). A plug load control strategy devised to match plug load use with occupancy is a huge untapped potential for energy savings (Lobato et al., 2012). (Kamilaris, Kalluri, Kondepudi, \& Kwok Wai, 2014) discussed energy metering, taxonomy and modes of operations of office equipment. (Kaneda, Jacobson, \& Rumsey, 2010; Kawamoto, Shimoda, \& Mizuno, 2004; Kwong, Goh, Adam, \& Raghavan, 2014; MACEBUR, 1998; Mungwititkul \& Mohanty, 1997; Nordman, Meier, \& Piette, 2000; Poll \& Teubert, 2012; Webber et al., 2006) indicated that office equipment is usually left on during unoccupied periods. (Gandhi \& Brager, 2016) indicated that behavior based control can achieve cost effective energy savings. (Acker, Duarte, \& Wymelenberg, 2012; Kaneda et al., 2010; Metzger et al., 2012) proposed occupancy and load sensing plug strips to automatically shut down electric equipment and save energy. (Arnold, Sankur, \& Auslander, 2013; Weng, Balaji, Dutta, Gupta, 
\& Agarwal, 2011) presented a control algorithm to manage few local office plug loads to meet the load shed target while minimizing occupant's inconvenience. When modeling plug loads in buildings, they are assumed to be static devices with predetermined parameters, leading to simulation results exhibiting low fidelity (Kamilaris, Kalluri, Kondepudi, \& Tham, 2014).

Based on the literature, it can be concluded that there is a lack of optimal DR management that can control all major loads (HVAC, lighting and plug loads) and quantify DR potential in small and medium-sized commercial buildings. Previous studies have rarely reported comfort performance; it is important that buildings provide comfortable indoor environment necessary for productivity of occupants (Aduda, Labeodan, Zeiler, Boxem, \& Zhao, 2016). For HVAC control, literature review shows that mostly buildings apply global temperature adjustment to achieve HVAC energy savings. This scheme may not be able to meet occupant comfort satisfaction, as all thermal zones do not behave the same. For lighting control, typically daylight control with automatic light switching or loosely coupled photoelectric dimming is implemented in buildings. For plug load control, there are a limited number of studies discussing control of plug loads at building level. Building's plug loads are usually modeled by lumping all plug loads together, and the total plug load power consumption is determined by using a constant plug load density (i.e. $\mathrm{W} / \mathrm{m}^{2}$ ) together with the plug load schedule. There is a need to explore load duration curves of key plug loads in order to better map how usage patterns affect consumed power (Kamilaris, Kalluri, Kondepudi, \& Kwok Wai, 2014) and help in automating DR management in peak load scenarios (Weng et al., 2011). There is also a knowledge gap with regard to impacts of controlling commercial building's plug loads on the building load profiles (Acker et al., 2012).

To address the above knowledge gaps, the authors propose integrated automation for optimal control of major loads in commercial buildings including cooling, lighting and plug loads while occupant environmental preferences, mainly thermal and lighting, are maintained. The integrated automation enables a smart building to minimize its power and energy usage, taking into account the interaction among lighting, HVAC and plug loads. The proposed approach is validated by experimentation conducted on a simulated medium-sized office building modeled in EnergyPlus, which reflects an existing commercial building in Virginia, U.S. However, the proposed approach can be applicable to any type and size of commercial buildings.

\section{Model of a medium-sized commercial building and its loads by type}

This section summarizes the simulated medium-sized office building model used as a basis to develop the proposed approach.

The simulated medium-sized office building model is based on the U.S. Department of Energy (DOE)'s medium-sized reference building model available in (DOE, 2011a), reflecting buildings in Virginia/Maryland area with the post-1980 construction. (Cui, Wu, Hu, Weir, \& Li, 2016; Li, Wen, \& Bai, 2016) have simulated these reference buildings in lieu of real buildings for model development and evaluation. This building was modeled in EnergyPlus version 8.3- a widespread building energy simulation tool - which provides more accurate peak electric load savings than baseline methods. EnergyPlus is a whole building energy modeling and simulation tool, which ensures integrated building and system analysis and can predict dynamic behavior of 
building systems under changing internal and external conditions (Crawley et al., 2001; Karaguzel \& Lam, 2011; Royapoor \& Roskilly, 2015). Based on user's description of building envelope, mechanical systems, building location, dynamically changing outside weather conditions, changes in internal loads (e.g. occupants and lights) and other inputs, EnergyPlus calculates the heating and cooling loads at user specified time step (1-minute interval) needed to maintain thermal control set points, building energy consumption and other parameters visualizing actual building performance (Melki \& Hayek, 2009).

Input data for building envelope, climate conditions, and operating characteristics, internal and external loads for developing the simulated medium-sized office building model in EnergyPlus are discussed below:

Building envelope: The simulated medium-sized office building for this study is a $4,980 \mathrm{~m}^{2}$ three-story building. It is rectangular shaped $50 \mathrm{~m}$ by $33 \mathrm{~m}$. Windows have the height of $1.22 \mathrm{~m}$ and are distributed evenly in continuous ribbons around the perimeter of the building. The simulated medium-sized office building's north axis is specified to the North. Figure 1 shows the simulated medium-sized office building's axonometric view and location.

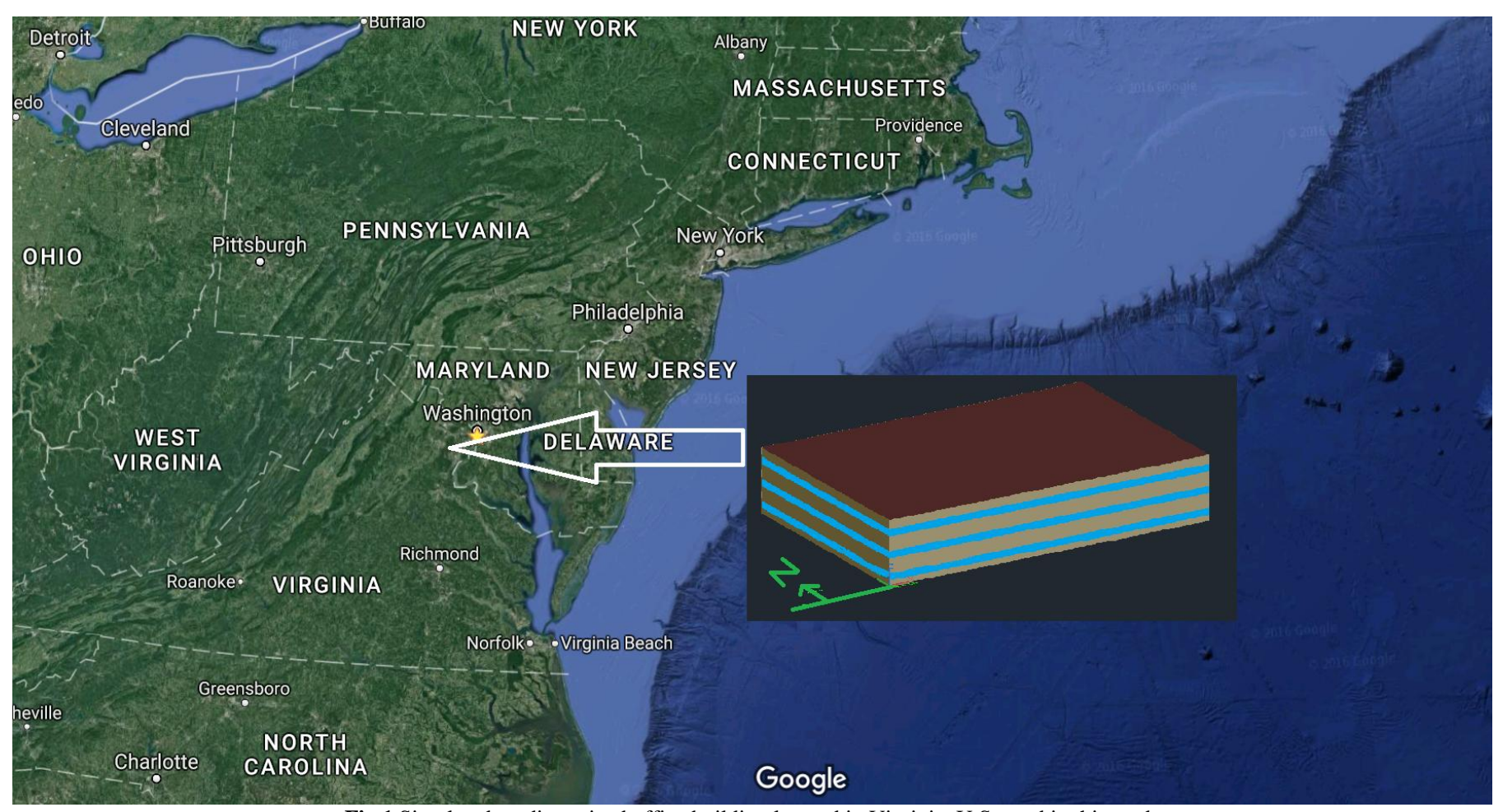

Fig.1 Simulated medium-sized office building located in Virginia, U.S. used in this study

Weather data: The study has been performed for a summer season when the cooling load is high during afternoon hours. The weather data used is of Ronald Reagan Washington National airport, U.S. Weather data, in the EnergyPlus weather format is available from (DOE, 2011b). Figure 2 shows the shows the outdoor air dry-bulb temperature for a summer day used in this study. From around noon to $6 \mathrm{pm}$ outside air temperatures are higher than $30^{\circ} \mathrm{C}$. Maximum outdoor air temperature is about $32^{\circ} \mathrm{C}$ from $3 \mathrm{pm}$ to around $4: 15 \mathrm{pm}$.

Occupancy model: The method used for calculating nominal number of occupants in each zone is area/person specified as 5 
persons per $93 \mathrm{~m}^{2}$ of gross floor area. The occupancy schedule on a typical weekday used in this study is shown in Figure 2 . The simulated building follows typical occupancy patterns for office building with peak occupancy between 8am to 5pm on weekdays and a decrease during lunch-time between $12 \mathrm{pm}$ to $1 \mathrm{pm}$. Activity level value is set at 120W/person (ASHRAE, 2013b), appropriate for office activities, and an internal algorithm determines fractional latent and sensible heat gains. $30 \%$ of the total sensible energy emitted by people is long wavelength radiation gain in a zone while the rest is convective heat gain.

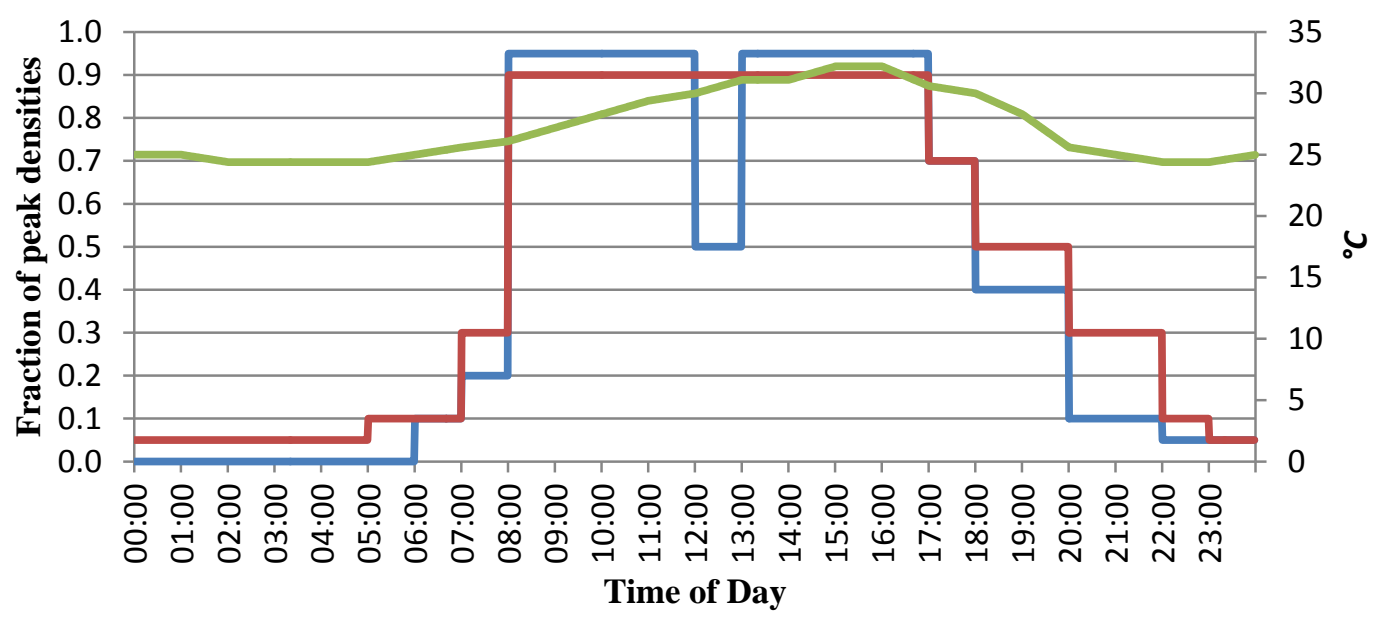

Occupancy Interior lights _ Outdoor air dry-bulb temperature

Fig.2 Simulated medium-sized office building typical weekday schedules and outdoor air dry-bulb temperature used in this study

HVAC load model: Each floor of the simulated medium-sized office building has a package rooftop variable air volume (VAV) system. The HVAC is "on" one hour before occupants arrive at the building to bring the space to the desired temperature and is "off" one hour after most of the occupants have left the building, i.e. from 6am to 10pm. For a summer weekday - from 6am to $10 \mathrm{pm}$ - the normal cooling set point is $24^{\circ} \mathrm{C}$. During off-hours set back strategy is applied and the cooling temperature set point is $26.7^{\circ} \mathrm{C}$. The simulated building has five thermal zones - four perimeter zones and one core zone - on each floor. For each of the three floors, perimeter zone 1 faces south, perimeter zone 2 faces east, perimeter zone 3 faces north and perimeter zone 4 faces west. The core zones on all floors are not exposed to exterior building conditions. The HVAC load model for Direct Expansion (DX) unit with VAV fans available in EnergyPlus is used in this study.

Interior lighting load model: The interior lighting load model available in EnergyPlus is used in this study which allows specification of design power level, operation schedule and thermal distribution of heat generated from light sources. Design level calculation method used is watts/area and the ambient electric lighting power density for the entire simulated building is 17 $\mathrm{W} / \mathrm{m}^{2}$. The interior lighting schedule on a typical weekday used in this study is shown in Figure 2. $90 \%$ interior lights are energized from $8 \mathrm{am}$ to $5 \mathrm{pm}$ and $5 \%$ remain energized from $11 \mathrm{am}$ to $5 \mathrm{am}$.

Electrical input to light appears as heat dissipated into building zones. EnergyPlus divides this heat into fraction that goes into 
the zone return air and does not contribute to cooling load, fraction emitted into the zone as long wave thermal radiation, fraction that is emitted into the zone as visible - short-wave - radiation and fraction convected to the zone air. The sum of all heat gains should be equal to 1(BigLadderSoftware, 2015). The magnitude of these fractions depends upon the type of lamp and luminaire, HVAC and building space design (DiLaura, Houser, Mistrick, \& Steffy, 2011b). The reference medium-sized office building considers a recessed fluorescent luminaire with some of the lamp heat directed to the plenum return air stream. Hence, $40 \%$ of the heat is added to the return air, $40 \%$ emitted as thermal radiation and $20 \%$ as visible radiation (Chantrasrisalai \& Fisher, 2007).

Plug load models: Office buildings have plug loads, such as office equipment, refrigerators, coffee makers, beverage vending machines. As there are four tenants in the building, it is assumed that the mid floor has twice as many tenants than other floors (Thornton, Wang, Lane, Rosenberg, \& Liu, 2009), which leads to higher number of office equipment and plug load density for the mid floor. The type and quantity of plug load equipment considered is as per Pacific Northwest National Laboratory (PNNL) plug loads study for medium-sized office buildings (Thornton et al., 2009). To simulate plug loads in this study, instead of lumping all plug loads together, a dynamic plug load model with 1-minute intervals has been developed for individual plug loads. This results in $7.86 \mathrm{~W} / \mathrm{m}^{2}$ plug load power density for the entire simulated building.

Electric plug loads produce both radiant and convective heat gains which impact the time and magnitude of peak load. Convective heat gain is converted instantly to cooling load while radiant heat gain is first absorbed by building mass and later converted to cooling load (Hosni, Jones, \& Xu, 1999; Wilkins \& Hosni, 2000). Radiant and convective heat gains are selected for some office equipment based on available experimentation results by (ASHRAE, 2013a; Wilkins \& Hosni, 2000) and are presented in Table 1. Authors in (Hosni et al., 1999) provide guideline that if no information is available total heat loss from equipment can be estimated as $20 \%$ by radiation and $80 \%$ by convection. Hence, it is assumed that for vending machine, water cooler, fan and miscellaneous appliances, heat produced is $20 \%$ is radiant and $80 \%$ convective.

Table.1 Radiant and convective heat gain from office equipment (ASHRAE, 2013a; Wilkins \& Hosni, 2000)

\begin{tabular}{|c|c|c|}
\hline & \multicolumn{2}{|c|}{ Heat gain (\%) } \\
\hline & Radiant & Convective \\
\hline Computer - desktop & 10 & 90 \\
\hline Computer - laptop & 75 & 25 \\
\hline Monitor & 40 & 60 \\
\hline Laser printer & 30 & 70 \\
\hline Copier & 22 & 78 \\
\hline Fax machine & 32 & 68 \\
\hline Refrigerator & 25 & 75 \\
\hline Coffee machine & 33.33 & 66.67 \\
\hline
\end{tabular}


Typical weekday profiles of office electric plug loads - including beverage vending machines, refrigerators, coffee makers, water coolers, portable fans, desktop computers and monitors, laptops, fax machines, laser printers and copy machines - are generated in EnergyPlus, their usage is randomized to depict real-time occupant behavior, each of which is discussed as follows:

1) Beverage vending machines

A typical vending machine comprises a compressor, a circulation fan, a fluorescent lighting system, and electronics (Ritter \& Hugghins, 2000). Two types of vending machine models have been developed in EnergyPlus using data from (Ritter \& Hugghins, 2000). First vending machine's compressor is on for 5 minutes consuming 761W. Compressor cycling time, i.e. time elapsed from one compressor energization to the next, is 7 minutes during which only the circulating fans and lights are on consuming $281 \mathrm{~W}$. Second vending machine's compressor runs for 8 minutes and consumes $776 \mathrm{~W}$. Compressor cycling time is 15 minutes consuming $276 \mathrm{~W}$.

\section{2) Fax machines}

Fax machines are always operating either in an active mode or a standby mode (Roth, Goldstein, \& Kleinman, 2002). During an active mode a fax machine is either transmitting or sending fax. In a stand-by mode, a fax machine is ready to but not carrying out any operation. For a typical use, a fax machine is in an active mode for 10 minutes a day, during which its power consumption is $30 \mathrm{~W}$ and 1430 minutes a day in a standby mode, during which it consumes $15 \mathrm{~W}$ (Roth et al., 2002). It is assumed that each faxing activity takes at least 1 minute to complete. Randomized fax usage is assumed during the office working hours to generate a load profile of fax machine in the simulated office building.

\section{3) Computers-servers}

A server refers to a computer that is not directly associated with a specific human user and provides common functions to a group of users. It performs back-end processing invoked on a scheduled basis or by other computers. Server computer operates in an active mode around the clock (Roth et al., 2002) with an active power draw about $50 \%$ of its nameplate power (Goldstein \& Bloom, 2014). Server's power range is between $50 \mathrm{~W}$ to $270 \mathrm{~W}$. In this study, active mode power consumption is considered 75W (Kawamoto et al., 2002).

\section{4) Computers-desktop}

Desktop computers are either in an active mode, a low power or an off mode. Desktop computers are in the off mode during non-office hours. A desktop computer can be in a standby mode when an employee is unseated during lunch time or attending a meeting. Occupants are usually seated at their desks for less than one third of the average workday (Metzger et al., 2012). Authors in (Webber et al., 2006) found in a survey about $94 \%$ of computers do not have power management feature and the turn off rate is $36 \%$. This implies that employees usually do not turn off computers or disable power settings. A desktop computer operates in an active mode for 9 hours a day consuming 55W; in a low power mode for 2 
hours a day consuming 25W; and in a standby mode for 13 hours a day consuming $1.5 \mathrm{~W}$ (Kawamoto et al., 2001). Figure 3(a) shows the typical weekday power consumptions of desktop computers generated in EnergyPlus.

\section{5) Computers-laptops}

Laptop computers are either in an active mode, a low power, an off mode or unplugged. During non-office hours occupants usually unplug laptops to take them home. A power analyzer was used to measure a laptop's power consumption. The active power consumption fluctuates around $37 \mathrm{~W}$ depending upon processor's activity. During an idle mode the power consumption drops to $14 \mathrm{~W}$ and increases to $18 \mathrm{~W}$ after 2 minutes when the screen saver runs. Findings from (Kawamoto et al., 2001), show that a laptop on a regular weekday in an office building is in an active mode for only about 2.7 hours, and in a low power mode for about 8.7 hours. Unlike desktop computers, laptop computers are in an active mode for only a few hours due to their power management feature. Figure 3(b) shows the power consumptions of laptop computers on a typical weekday generated in EnergyPlus.

\section{6) Liquid Crystal Display (LCD) monitors}

A typical 17inch LCD monitor for office buildings has been modeled. The monitor can be in an active, a low power or an off mode. During an active mode, power draw is usually less than the nameplate power by the factor of 3 or more (Goldstein \& Bloom, 2014). A low power mode is defined when the screen is powered down. An off mode is when the screen is switched off. According to (Kawamoto et al., 2001; Roth et al., 2002) a monitor is in an active mode for 6 hours a day consuming $16.7 \mathrm{~W}$, in a low power mode for 5 hours consuming $4.8 \mathrm{~W}$, and in a standby mode for 13 hours a day consuming $0.8 \mathrm{~W}$. The survey conducted by authors in (Webber et al., 2006) shows that the turn off rate for LCD monitors is about $18 \%$. Power consumption profiles of monitors on weekdays are generated in EnergyPlus as shown in Figure 3(c).

\section{7) Laser printer}

Laser printers are usually shared resources between several users in a computer network (Roth et al., 2002). Shared equipment is usually left on indefinitely (Metzger et al., 2012). Power consumption of two different laser printers was measured with a power analyzer. Printer 1 consumes $800 \mathrm{~W}$ while printing a page in about 10 seconds and $4.4 \mathrm{~W}$ during standby. Printer 2 consumes 548W while printing a page in about 30 seconds and $10.9 \mathrm{~W}$ during standby. Findings from (MACEBUR, 1998) show that laser printers are active, i.e., perform printing operations, for about 43 minutes on a weekday. Other studies (Kawamoto et al., 2001; Roth et al., 2002; Wilkins \& Hosni, 2000) do not report laser printer usage in active mode. It is assumed that printer 1 prints no less than 6 pages at a time and printer 2 prints no less than 2

pages at a time, and the minimum printing activity takes 1 minute to complete. Figure 3(d) shows the power consumption for the two laser printers on weekdays generated in EnergyPlus. 


\section{8) Copy machine}

Copy machines are shared resources, and like printers are left on indefinitely. Power consumption of two different copy machines was measured with a power analyzer. Copy machine 1 consumes $900 \mathrm{~W}$ while copying a page in about 10 seconds and $6.5 \mathrm{~W}$ during standby. Copy machine 2 consumes $800 \mathrm{~W}$ while copying a page in about 10 seconds and $4.4 \mathrm{~W}$ during standby. Findings from (Meyer \& Schaltegger, 1999) show that copy machines are active typically for about 37 minutes on a weekday. Other studies (Kawamoto et al., 2001; Roth et al., 2002) do not report copier usage in active mode. It is assumed that the two copy machines copy no less than 6 pages at a time, and the minimum copying activity takes 1 minute to complete. Figure 3(e) shows the power consumption for the two copy machines on weekdays generated in EnergyPlus.

9) Water cooler

Water coolers deliver water between $5^{\circ} \mathrm{C}$ to $10^{\circ} \mathrm{C}$. When switched on, the unit cools the water at ambient temperature to the desired temperature. Water coolers are typically switched on for 24 hours a day. For the modeled water cooler - based on different manufacture datasheets - it is assumed that the compressor is on for 7 minutes and consumes $260 \mathrm{~W}$ and is off for 5 minutes consuming no power.

\section{0) Coffee maker}

Power consumption of a coffee machine was measured with a power analyzer. It was observed that the machine is never unplugged by occupants. When switched off but plugged in, it consumes around $8.3 \mathrm{~W}$. When switched on, but not in use it consumes around $10.4 \mathrm{~W}$ with brief power surges to keep the water hot. While brewing $1316 \mathrm{~W}$ is consumed. The brewing time is assumed to be no less than one minute. Based on the measured data, the power consumption profile for the modeled coffee maker on weekdays is generated in EnergyPlus, as shown in Figure 3(f). Increased use is observed during early morning and late afternoon hours.

\section{1) Refrigerator}

The refrigerator model used in this study has been developed by measuring the power consumption of a refrigerator with a power analyzer. The refrigerator is on for 8 minutes during which it consumes $135 \mathrm{~W}$. If the door is opened, there is an additional 40W power drawn due to the incandescent light bulb inside the refrigerator and duration of on time exceeds. The off mode duration is 15 minutes and during this time there is no power consumption. A defrost cycle happens every 30-40 hours and lasts for about 20 minutes consuming 365W. The defrost cycle is followed by a long refrigerator operating duration. Figure 3(g) shows the power consumption for the modeled refrigerator generated in EnergyPlus. Increased refrigerator door opening is observed during morning hours, lunch hours, and in the evening hours. 


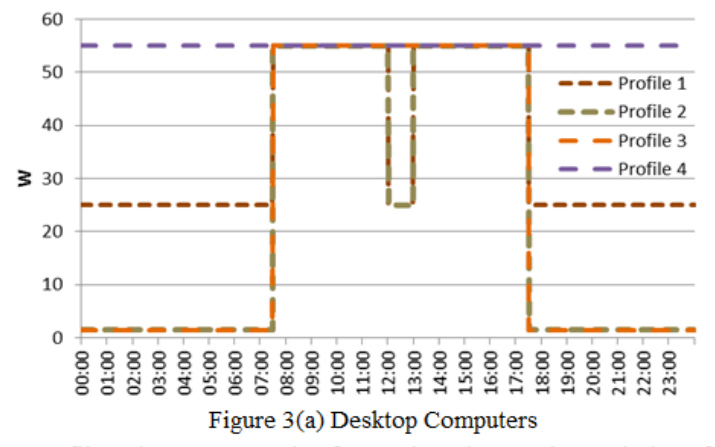

Profile 1: low power mode of operation when not in use during office and non-office hours

Profile 2: low power mode of operation when not in use during office hours and turned off during non-office hours

Profile 3: active mode of operation during office hours and turned off during non-office hours

Profile 4: active mode of operation all day

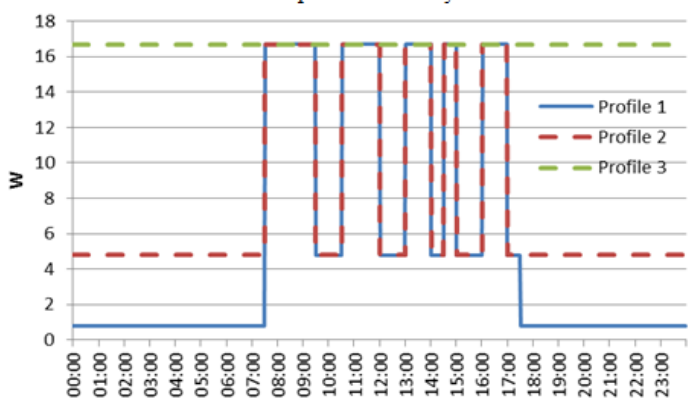

Figure 3(c) LCD Monitors

Profile 1: low power mode of operation when not in use during office hours and turned off during non-office hours

Profile 2: low power mode of operation when not in use during office and non-office hours

Profile 3: active mode of operation all day

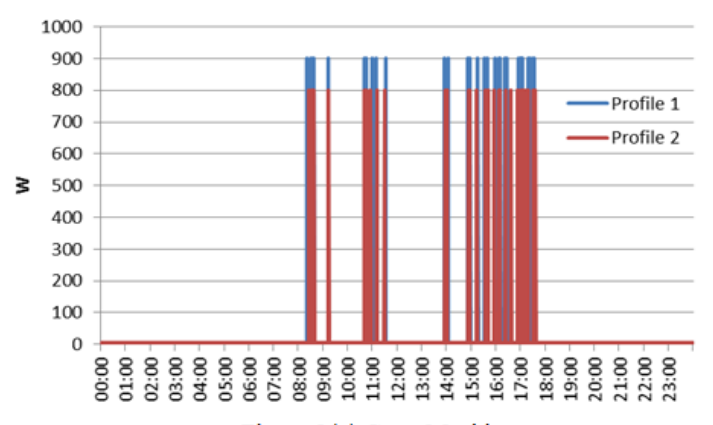

Figure 3(e) Copy Machines

Profile 1: copy machine 1, in active mode of operation for 37 minutes Profile 2: copy machine 2, in active mode of operation for 37 minutes

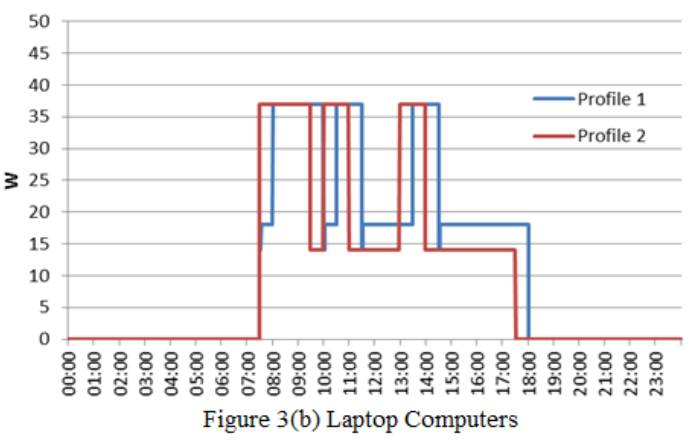

Profile 1: screen saver in operation

Profile 2: screen saver deactivated

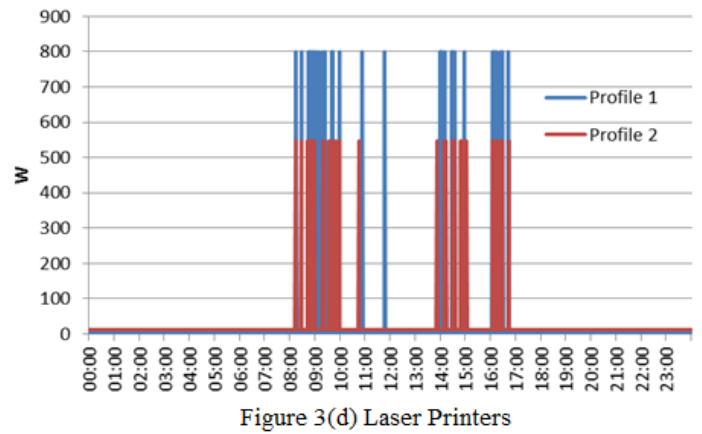

Profile 1: printer 1, in active mode of operation for 43 minutes Profile 2: printer 2, in active mode of operation for 43 minutes

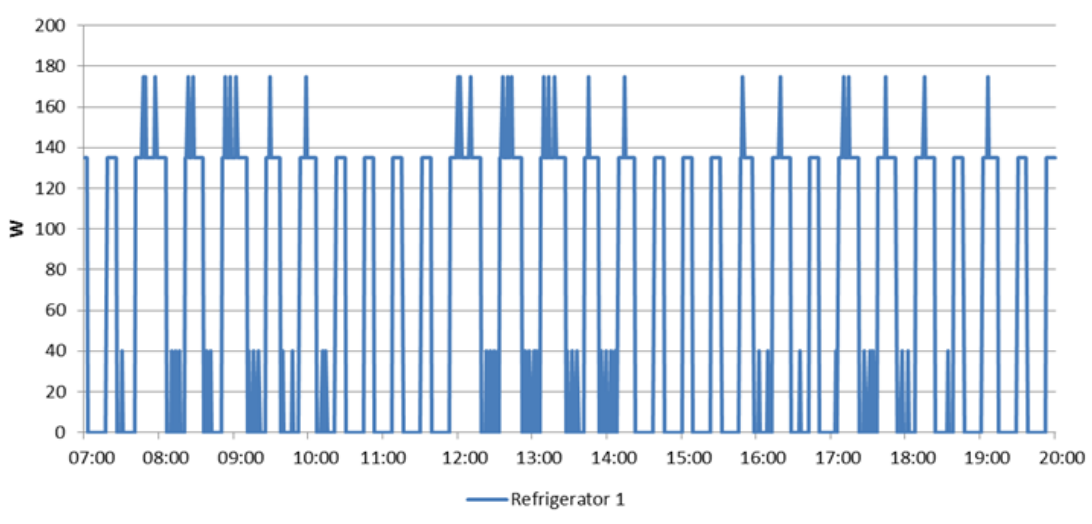

Figure 3(g) Refrigerator

Fig. 3 Power consumption profiles of various modeled plug loads on weekday used in this study 


\section{2) Portable fan}

A portable fan consumes around 30W when operating (Weng et al., 2011). Based on this data, random weekday power consumption profiles are generated in EnergyPlus to depict occupant behaviors.

\section{3) Miscellaneous Appliances}

There is a wide range of miscellaneous equipment in office buildings like cell phone or iPad chargers, table radio, adding machine, battery charger, portable stereo, portable CD player, stapler, corded phone, etc. These miscellaneous appliances consume around 4W power (Thornton et al., 2009). The miscellaneous appliances follow the schedule shown in Figure 4. From 8 am to $5 \mathrm{pm}$ equipment usage is about $90 \%$, reducing to $80 \%$ during lunch hours from $12 \mathrm{pm}$ to $1 \mathrm{pm}$. After $5 \mathrm{pm}$, as number of occupants decrease, gradually equipment usage reduces to $40 \%$ for unoccupied periods.

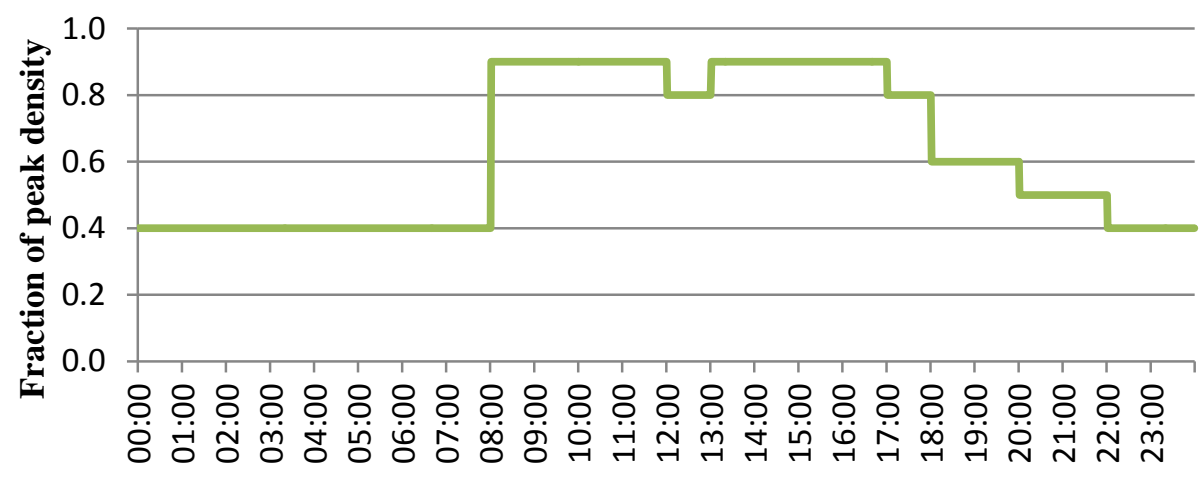

Time of Day

Miscellaneous electrical equipment

Fig.4 Miscellaneous appliances weekday schedule used in this study

\section{The proposed methodology for optimal control of end-use loads}

Typically a DR event on a weekday can be at any time between 1pm to 7pm during summer (CPSEnergy, 2016; PJM, 2016). The DR event selected for this analysis on a summer day is between $2 \mathrm{pm}$ to $5 \mathrm{pm}$. In this study, DR savings correspond to the difference between simulated building load profiles with and without a DR strategy. This provides more accurate DR savings than estimation techniques. Minute-by-minute load simulation is performed to enable the most accurate representation of building loads. Note that, while most traditional Building Energy Management (BEM) products enable control of building loads in 15-minute intervals, with the availability of Internet-of-Things (IoT) devices and powerful computers, recently released BEM software platforms, such as Building Energy Management Open Source Software (BEMOSS) (VirginiaTech, 2016), are capable of monitoring and control building loads at a fine resolution of 1-minute intervals or less. This justifies the 1-minute resolution DR control presented in this paper.

\subsection{Overall algorithm}


The optimal control algorithm for end-use loads is designed using EnergyPlus EMS. The EMS manager, core component of the EMS module, co-ordinates activities of EMS objects like sensors and actuators with the overall EnergyPlus simulation. The EMS module uses a simple programming language, EnergyPlus Runtime Language (Erl), to specify control algorithms based on IF-THEN-ELSE statements and other logic structures explained in detail in (DOE, 2013). The EMS works by polling a set of sensors and retrieves information about external environmental conditions (e.g., daylight illuminance levels), internal building conditions (e.g., current electric light level or space temperature set point in a zone), HVAC and other equipment conditions. This sensor data becomes input variable for EMS control algorithms specified in Erl and is used to direct various types of control actions. Remote actuators are controlled to make changes to system operations once the EMS passes judgment e.g. change thermostat set points, dim lights or shut down low priority plug loads. This emulates, inside EnergyPlus, the same type of controls that can be implemented with digital EMS in real buildings.

Specifically, the overall algorithm and the control methods for HVAC, lighting and plug loads in buildings are explained in detail as follows.

During a DR event EMS controls building operation. The flowchart of the designed algorithm is presented in Figure 5 and is explained as follows:

- First, the EMS module and the zone cooling set point, light and plug loads actuators are activated and override the normal building operation during a DR event.

- At each time-step the EMS sensors retrieve the PMV index, daylight illuminance levels and cooling set points of each zone on all floors along with light and plug load schedules. This data is mapped to EMS variables to be used in control algorithms specified in the EMS program.

- At the beginning of each time step the EMS Program Calling Manager calls the EMS program - which contains instruction blocks of Erl code - to adjust each zone's cooling set points, lights and plug load levels as per the control algorithm. Building's cooling system attempts to meet the thermal load with the adjusted cooling set points, light and plug load levels for the relevant zones.

In this study, the algorithm designed for space temperature set point control, optimally adjusts each thermal zone's cooling set points to achieve peak load savings and maintain occupant thermal comfort. The algorithm designed for lighting control in EMS provides a tighter control of light levels, integrated with daylight, to maintain the illuminance at the desired set point in order to achieve more savings with good adaptability to the changing daylight conditions. In order to improve the accuracy of building simulation results and gain an insight into how individual plug load operation can be controlled during a DR event; instead of lumping together all the plug loads, the authors present a 1-minute resolution data set at individual plug load level that is integrated with EnergyPlus. This allows each key plug load to be individually controlled and shutdown during a DR event as 
each equipment's usage pattern affects the power it consumes. Control algorithms for HVAC, lighting and plug loads are described in detail in Sections 3.2, 3.3 and 3.4, respectively.

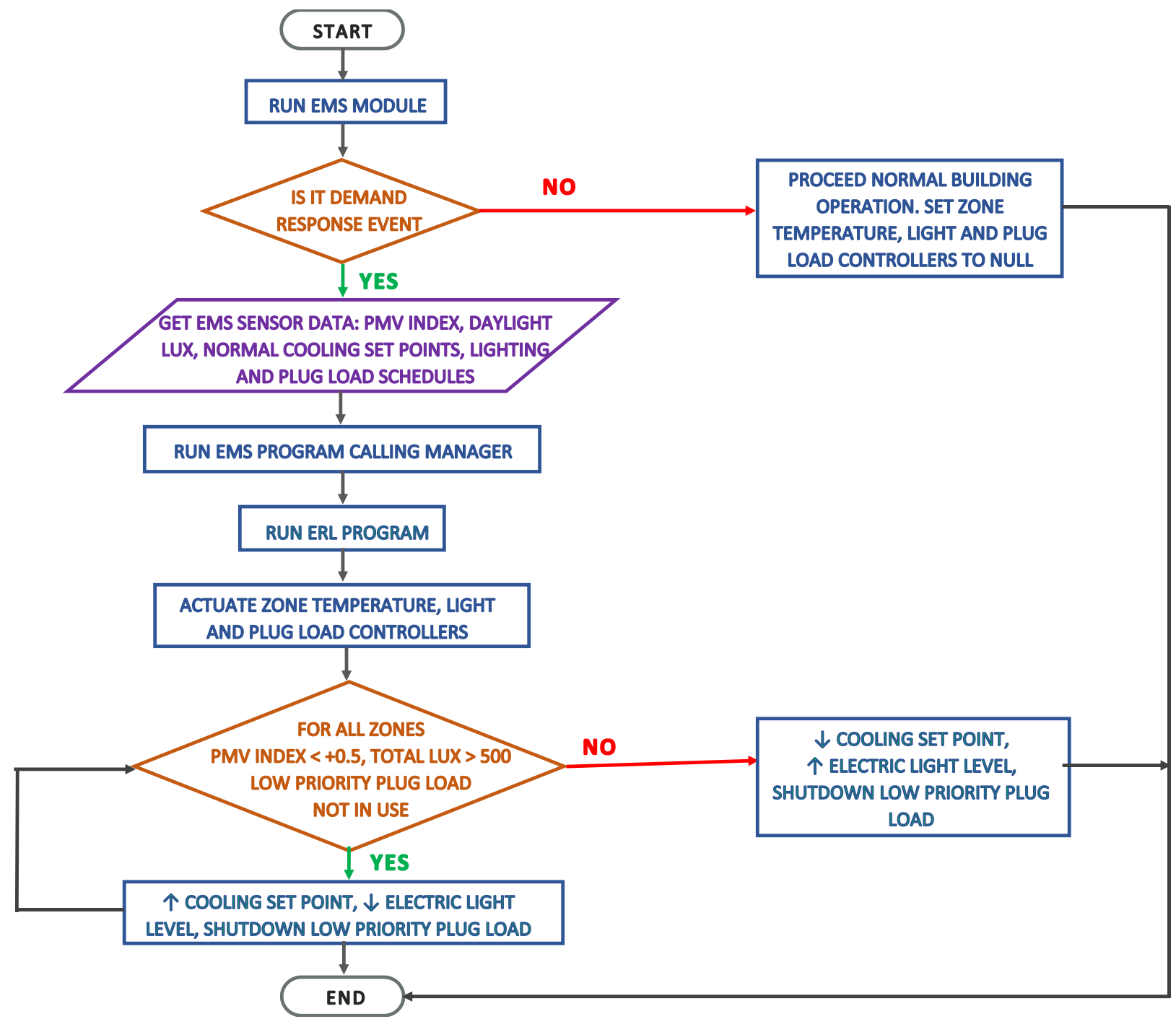

Fig.5 Optimal control algorithm for commercial building's end-use loads

\subsection{HVAC control}

In this study occupant thermal comfort is measured by using the thermal comfort index, Predicted Mean Vote (PMV) (Sehar et al., 2016). The PMV model, developed by Fanger takes into account air temperature, mean radiant temperature, relative humidity, air speed and two personal factors including activity and clothing, and can be applied to air-conditioned buildings to determine occupant thermal comfort. American Society of Heating, Refrigerating, and Air-Conditioning Engineers (ASHRAE) Standard 55 uses the PMV model to set the requirements for indoor thermal conditions (Turner, 2011). When PMV index is zero, thermal comfort is maintained; $+1,+2$ and +3 indicate slightly warm, warm and hot conditions respectively, while - $1,-2$ and 3 present slightly cool, cool and cold conditions respectively. PMV index range from -0.5 to +0.5 reflects comfortableness, and is used as a condition for air conditioning (Toftum, Andersen, \& Jensen, 2009). 
To perform HVAC control, the lower temperature limit in all zones is set at the normal operating cooling set point during occupied periods, or $24^{\circ} \mathrm{C}$, as described in Section 2. Each zone's cooling set points are adjusted repeatedly until a value is obtained at which the PMV index lies in between -0.5 and +0.5 and maximum peak load savings can be achieved. Once judgment has been made as per the EMS program instructions, EMS zone temperature control actuators increase or decrease thermostat cooling set points for all zones as per Equation 1. It is a schedule-based control since the normal operating cooling set point schedule is considered. The "SET" instruction performs control actions on the object to which it is mapped; here zone temperature control actuators. The offset varies at each time step, depending upon how much the cooling set points should be increased or decreased in order to maintain the PMV index within comfortable range. As soon as the DR event finishes, the normal cooling set points are resumed by setting the temperature control actuators for each zone to "Null". Null is a special structure that stops the actuator from overriding control.

$$
\text { SET } \quad T_{\text {cool }}^{\text {Adjusted }}=T_{\text {cool }}^{\text {Normal }}+\beta_{\text {cool }}
$$

Equation 1

Where:

$$
\begin{array}{lll}
T_{\text {cool }}^{\text {Adjusted }} & : & \text { Adjusted cooling set point }\left({ }^{\circ} \mathrm{C}\right) \\
T_{\text {cool }}^{\text {Normal }} & : & \text { Normal operating cooling set point }\left({ }^{\circ} \mathrm{C}\right) \\
\beta_{\text {cool }} & : & \text { Adjustment factor for cooling load }\left({ }^{\circ} \mathrm{C}\right)
\end{array}
$$

\subsection{Light control}

In this study illuminance, an index which assesses the quantity of light (Carlucci, Causone, Rosa, \& Pagliano, 2015), for office space is used for light control. The electric lights control algorithm has been developed in EMS that provides tighter control of electric lights to maintain an overall daylight plus electric light illuminance (in case of low daylight illuminance levels) at a set point value. This is unlike the daylight control object available in EnergyPlus which linearly reduces light electric power in response to increase in daylight illuminance. The developed EMS control maintains the targeted illuminance levels in both the perimeter zones with daylight illuminance and the core zones which are deprived of daylight illuminance. Dimming and shutting down the lights has an additional benefit as it reduces the cooling load.

In order to optimally utilize daylight, photosensors located in each zone communicate real time illuminance levels to the EMS which is configured with a threshold value of 500lux. This is as recommended by Illuminating Engineering Society of North America (IESNA) for office buildings (DiLaura, Houser, Mistrick, \& Steffy, 2000). As the perimeter zones are $15 \mathrm{ft}$ deep and receive uniform daylight illuminance due to the windows which are distributed evenly in continuous ribbons around the perimeter of the building, photosensors are located $3 \mathrm{ft}$ above ground (at desk height), at the center of each perimeter zone and $10 \mathrm{ft}$ away from the windows. EnergyPlus calculates daylight illuminance at the photosensor - which is dependent upon sky conditions (clear, clear turbid, intermediate and overcast), glass transmittance of windows, location of photosensor, window 
shading devices and reflectance of interior surfaces - through the daylight factor (DF)(Carlucci et al., 2015) which is ratio of interior illuminance to exterior horizontal illuminance and the external horizontal illuminance (Ramos \& Ghisi, 2010). The external illuminance is calculated in EnergyPlus through a model developed by (Perez, Ineichen, Seals, Michalsky, \& Stewart, 1990). The daylight illuminance available at the photosensor is added to the electric light illuminance - which is determined using Equation 2 (LightSearch, 2014; RapidTables, 2015) in the EMS program - to determine each perimeter zone's overall illuminance value.

$$
I_{\text {electric }}=\frac{P * \eta}{A}
$$

Equation 2

Where:

$\begin{array}{cll}I_{\text {electric }} & : & \text { Electric illuminance (lux) } \\ P & : & \text { Electric light input power }(\mathrm{W}) \\ \eta & : & \text { Luminous efficacy }\left(\frac{\mathrm{lm}}{\text { watt }}\right) \\ A & : & \text { Area of a zone }\left(\mathrm{m}^{2}\right)\end{array}$

$$
I_{\text {total }}=I_{\text {electric }}+I_{\text {sensor }}
$$

Where:

$$
\begin{array}{lll}
I_{\text {total }} & : & \text { Total illuminance (lux) } \\
I_{\text {sensor }} & : & \text { Daylight illuminance at the photosensor (lux) }
\end{array}
$$

A fluorescent lamp, most common in commercial building, is considered for the modeled office building. Fluorescent lamp efficacy is between 70 to $100\left(\frac{l m}{\text { watt }}\right)$ and the system - lamp + ballast - decreases by about $5 \%$ (DiLaura, Houser, Mistrick, \& Steffy, 2011a). An efficacy of $90\left(\frac{l m}{w a t t}\right)$ is considered. Each core zone on all floors has an area of $984 \mathrm{~m}^{2}$. Perimeter zones 1 and 3 , each has an area of $207 \mathrm{~m}^{2}$. Perimeter zones 2 and 4 , each has an area of $131 \mathrm{~m}^{2}$.

EMS light control operates as follows:

a) For core zones, which do not receive daylight illuminance, at each time step EMS core zone light control actuators increase or decrease the electric lighting levels as per Equation 4. It is a schedule-based control since the normal operating light schedule, shown in Figure 2, is considered. The adjustment factor is varied, and for each value electric light input power level is calculated and input in the Equation 2 to calculate the generated electric illuminance. Electric light input power level is selected which can maintain 500lux. 
b) For each perimeter zone, at each time step, firstly the daylight illuminance level from the photosensor is read by the EMS program. If this value is greater than 500lux than the zone light control actuator completely shuts down all lights by setting the adjustment factor in Equation 4 to zero. If the daylight illuminance level is less than 500lux than the EMS zone light control actuator increases or decreases the electric lighting level as per Equation 4 by varying the adjustment factor. Each calculated electric light input power level is input in the Equation 2 to calculate the generated electric illuminance. This electric illuminance is than added to the daylight illuminance as per Equation 3 to determine the overall zone illuminance. Electric light input power level is selected which can maintain an overall 500lux. As soon as the DR event finishes the normal light levels are resumed by setting the light control actuators for each zone to "Null".

$$
\text { SET } \quad P_{\text {light }}^{\text {Adjusted }}=P_{\text {light }}^{\text {Normal }} \cdot S_{\text {light }} \cdot \beta_{\text {light }} \quad \text { Equation } 4
$$

Where:

$\begin{array}{cll}P_{\text {light }}^{\text {Adjusted }} & : & \text { Adjusted lighting load power (W) } \\ P_{\text {light }}^{\text {Normal }} & : & \text { Normal lighting load power (W) } \\ S_{\text {light }} & : & \text { Normal lighting load schedule } \\ \beta_{\text {light }} & : & \text { Adjustment factor for lighting load }\end{array}$

\subsection{Plug loads control}

During a DR event, 50\% miscellaneous appliances, all portable fans and water coolers are shut down to achieve peak load savings by smart plugs and strips. The designed algorithm does not shutdown critical plug loads. Shutting down plug loads also reduces cooling load. Desktop and server computers/monitors are not shutdown during DR event since a desktop computer should not be de-energized without going through a proper shutdown procedure and a laptop, after de-energizing, if left in idle state can fully discharge before a proper shutdown procedure is performed (Lobato et al., 2012). Refrigerators, vending machines also remain on in order to maintain food quality and cold beverage temperatures. Other office equipment - like fax machines, copy machines and laser printers - are observed to consume low standby power. Their power consumption is high only when in an active mode - which lasts only for a short duration - therefore there is no need to shutdown these equipment.

Electric plug loads are shut down by EMS zone plug load control actuators as per Equation 5. It is also a schedule-based control since for each plug load - to be shut down - its normal operating schedule is considered. The adjustment factor is 0.5 , which allows shut down of $50 \%$ miscellaneous equipment in each zone, and zero for shutting down all portable fans and water coolers during a DR event. Plug load control actuators for each zone are set to "Null" at the end of DR event.

$$
\text { SET } \quad P_{\text {plug }}^{\text {Adjusted }}=P_{\text {plug }}^{\text {Normal }} \cdot S_{\text {plug }} \cdot \beta_{\text {plug }}
$$

Equation 5 
Where:

$\begin{array}{lll}P_{\text {plug }}^{\text {Adjusted }} & : & \text { Adjusted plug load power (W) } \\ P_{\text {plug }}^{\text {Normal }} & : & \text { Normal operating plug load power (W) } \\ S_{\text {plug }} & : & \text { Normal operating plug load schedule } \\ \beta_{\text {plug }} & : & \text { Adjustment factor for plug load }\end{array}$

\section{Simulation Results}

All simulations are performed at a resolution of 1-minute intervals and for a summer day. As the simulated office building is in the northern hemisphere and the fact that the sun rises north of due east and sets south of due west, during morning hours, the east facing zones (perimeter zones 2) receive high daylight illuminance. In the afternoon hours, the west facing zones (perimeter zones 4) receive high daylight illuminance. The south facing zones (perimeter zones1) receive sunlight higher than the north facing zones (perimeter zones 3). Incident daylight illuminance for the north zones is lowest of all orientations.

The normal operating cooling set point from $6 \mathrm{am}$ to $10 \mathrm{pm}$ is $24^{\circ} \mathrm{C}$ in all zones on all three floors. The PMV index during this time is mostly negative for all zones except for perimeter zone 4 - facing west - on the middle and top floors, the PMV index gets positive during the late afternoon hours (i.e., $4 \mathrm{pm}$ to $6 \mathrm{pm}$ ). This is due to increase in building cooling demand due to high internal load and outside air temperatures. The PMV index starts to decrease for all zones after $5 \mathrm{pm}$ due to decrease in simulated building's occupancy. From 10pm to $6 \mathrm{am}$ the normal operating cooling set point is increased to $26.7^{\circ} \mathrm{C}$ which makes the PMV index positive, especially for mid and top floor zones but not too high since there are no occupants in the simulated building and the internal building load is less.

\subsection{End-use loads control with EMS}

Actuators for temperature, light and plug load control are activated during the DR event, which is from $2 \mathrm{pm}$ to $5 \mathrm{pm}$.

As an example, Figure 6 shows the daylight plus electric lights illuminance levels and electric lights power consumption for the bottom floor's perimeter zone 2. This zone receives daylight. Location of the photosensor is as specified in Section 3.3. For the bottom floor's perimeter zone 2, electric lights are turned off by the EMS till around 2:30pm. After this daylight illuminance level gets lower than 500lux and gradually electric lights are turned on to maintain an overall illuminance level of 500lux. It can be observed that the EMS provides more lighting load savings than the daylight control object available in EnergyPlus which is unable to maintain the set point illuminance. 


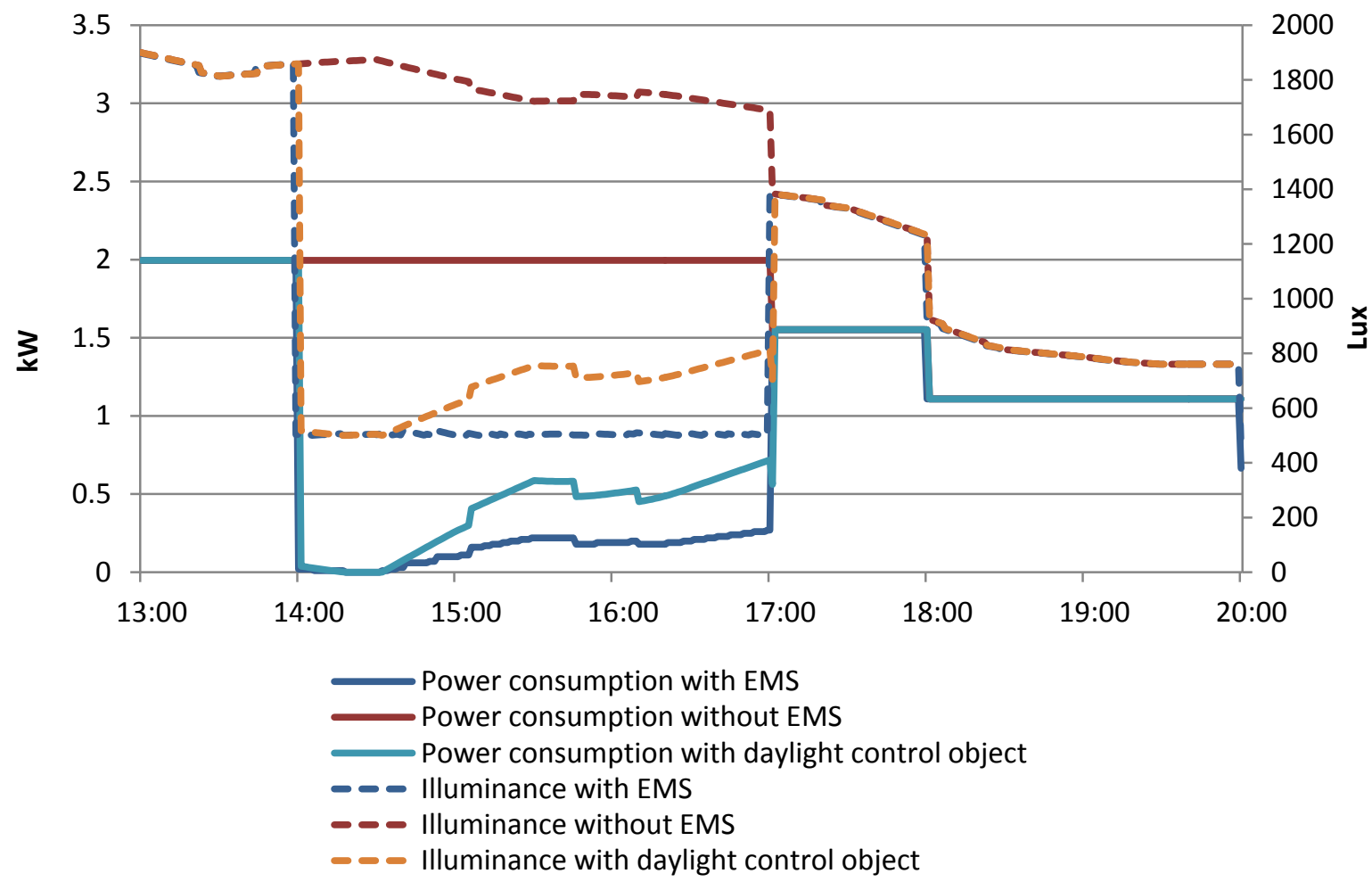

Fig.6 Bottom floor's perimeter zone 2 light power consumption and illuminance with and without EMS for a summer day

As an example, Figure 7 shows the PMV index and cooling set point for the bottom floor's perimeter zone 4 during the DR event. As cooling set points increase, the PMV index starts increasing due to less conditioning. Not every zone behaves the same, thus cooling set points are optimally adjusted in each zone to achieve maximum peak load savings and maintain thermal comfort. With EMS control, till 3:30pm, $27^{\circ} \mathrm{C}$ cooling set point can be maintained. Maximum peak load and energy savings are obtained with an upper limit of $3^{\circ} \mathrm{C}$ temperature offset from the original $24^{\circ} \mathrm{C}$ cooling set point which is explained in (Sehar et al., 2016). After 3:30pm, it is observed that by raising the cooling set point to $25^{\circ} \mathrm{C}, 1^{\circ} \mathrm{C}$ higher than the normal operating temperature of $24^{\circ} \mathrm{C}$, the PMV index increases rapidly. This is due to the fact that the zone 4 faces west and during late afternoon hours this zone gets more heat transferred from sunlight to the indoor space. After $3: 30 \mathrm{pm}$, a $25^{\circ} \mathrm{C}$ cooling set point maintains not only occupant thermal comfort but also achieves maximum peak load savings. It can be observed that if a global temperature adjustment control is applied and all zones cooling set points are raised to $27^{\circ} \mathrm{C}$ during DR event thermal comfort cannot be maintained. 


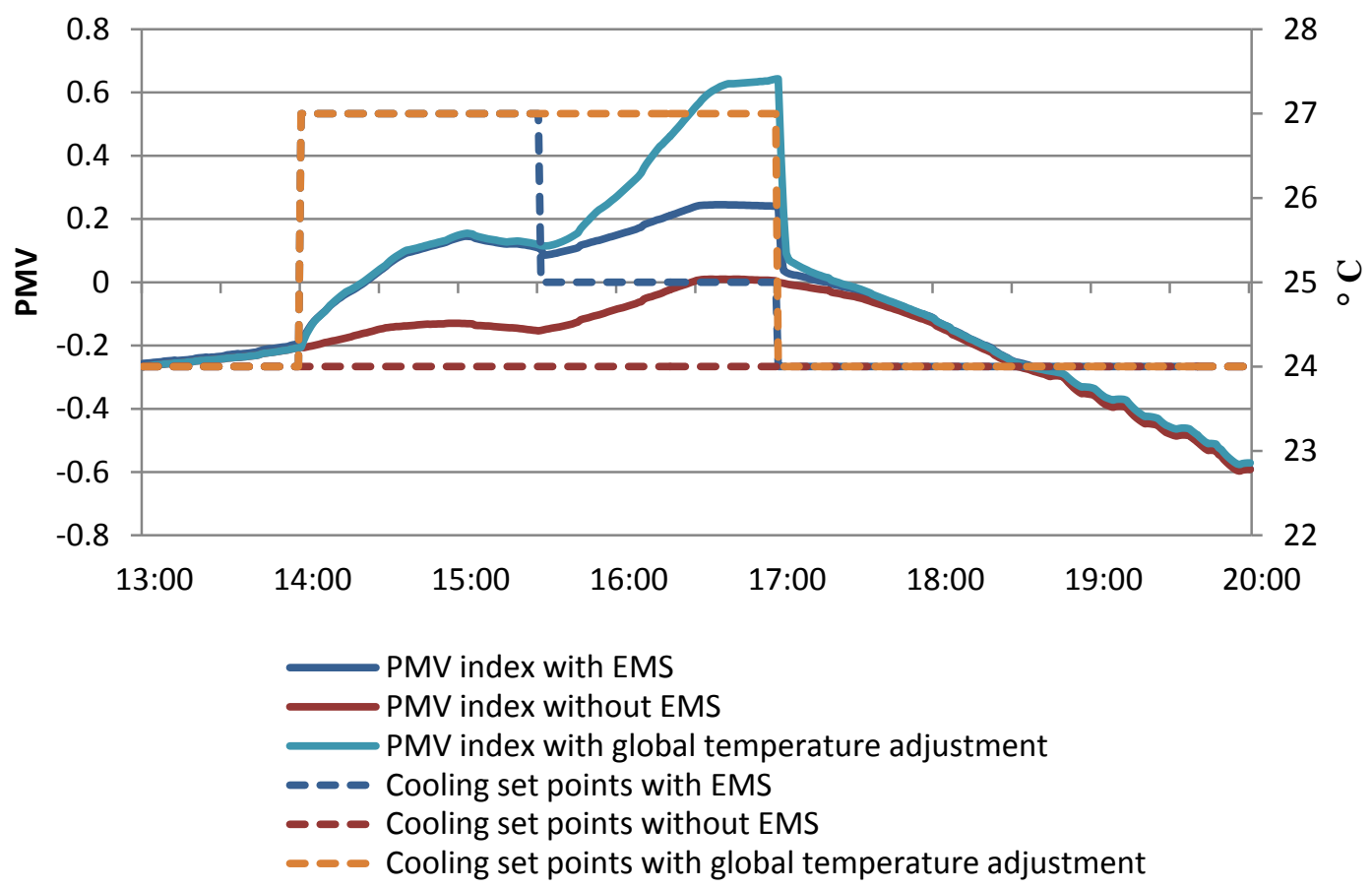

Fig.7 Bottom floor's perimeter zone 4 cooling set points and PMV index with and without EMS for a summer day

Figure 8 shows the peak load savings achieved for the aggregated plug loads profile during a DR event by shutting down water coolers, portable fans and $50 \%$ miscellaneous electric equipment.

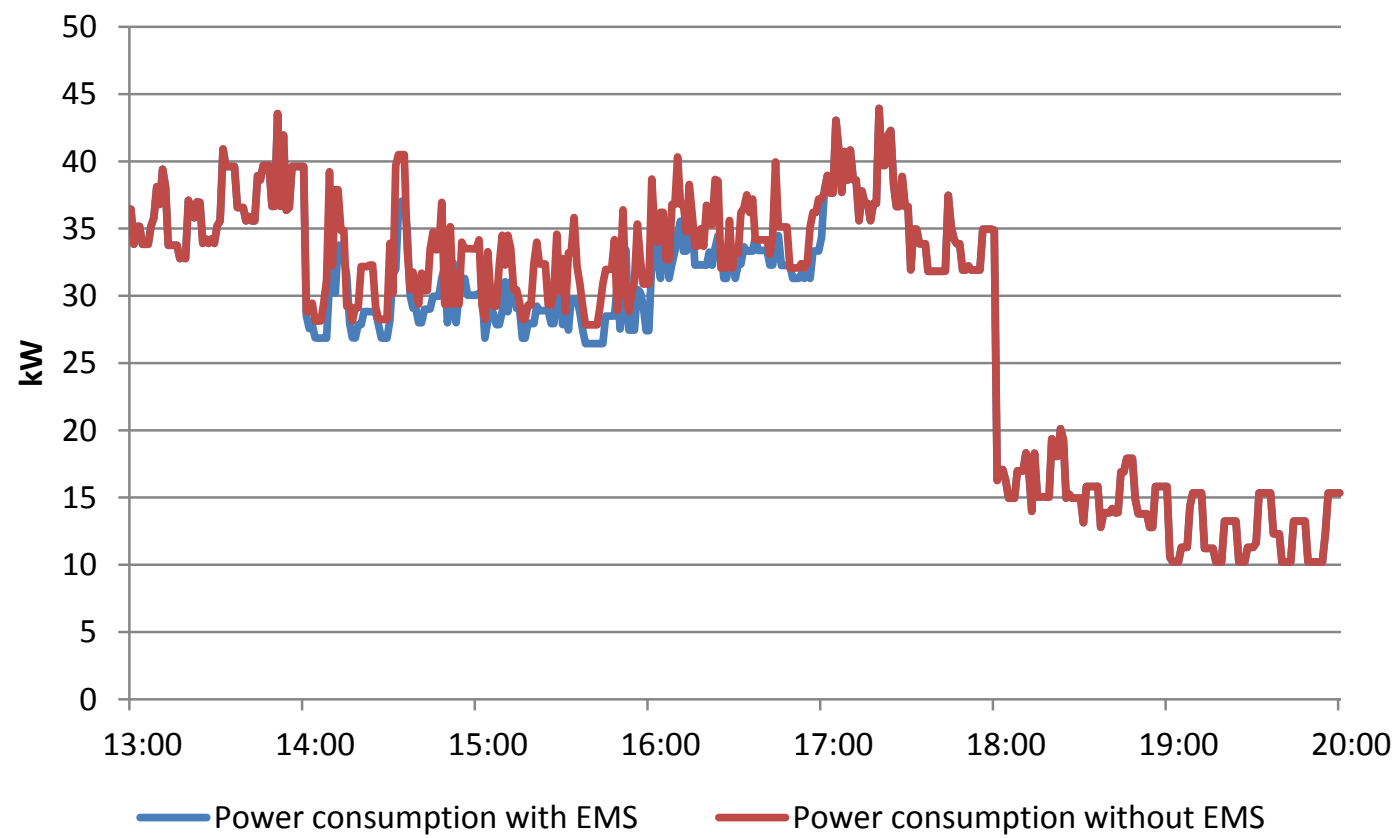

Fig.8 Aggregated electric plug loads power consumption profile with and without EMS for a summer day

4.2. Energy and peak load savings for all end-use loads control with EMS

The DR event from 2pm to $5 \mathrm{pm}$ has been investigated to evaluate peak load and energy savings potentials. 


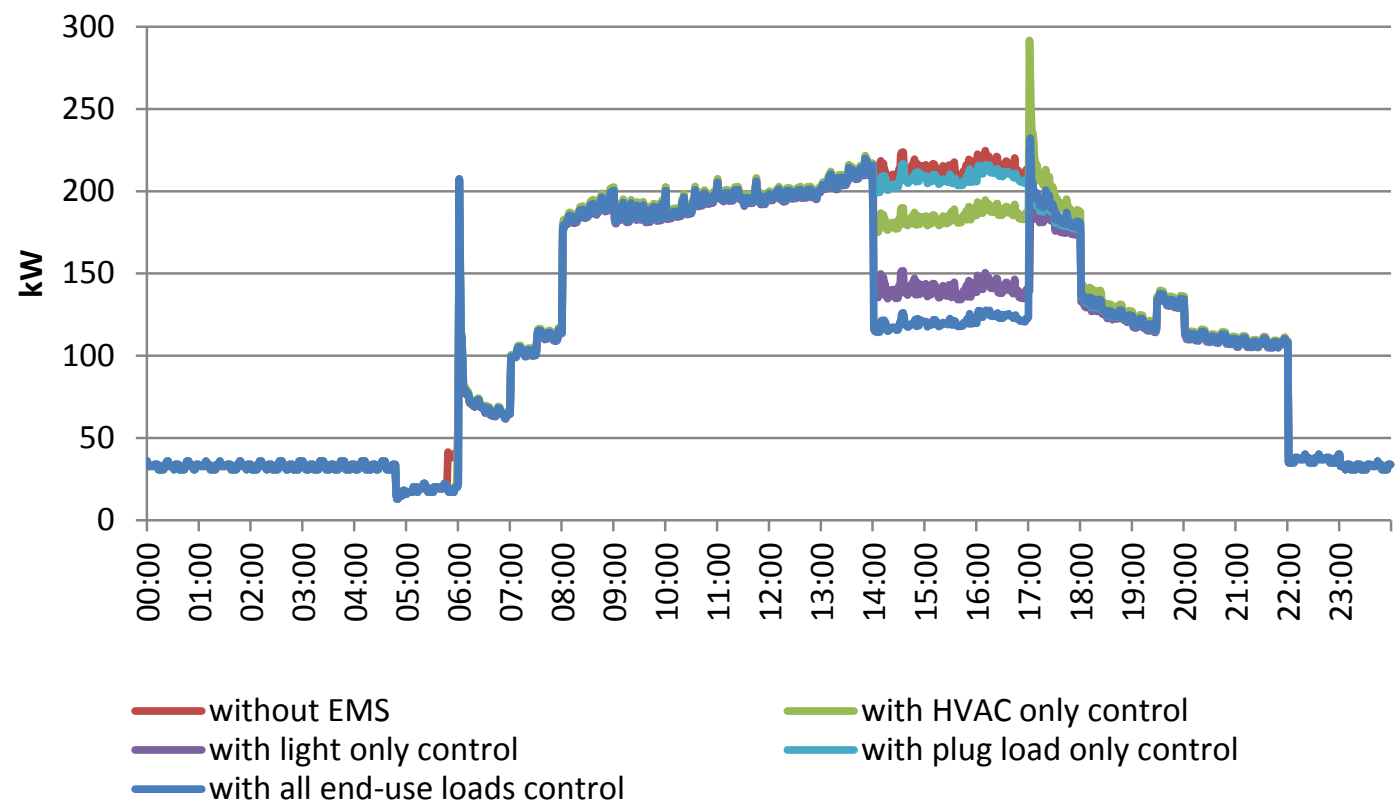

Fig.9 Simulated building peak load with and without end-use load control by EMS for a summer day

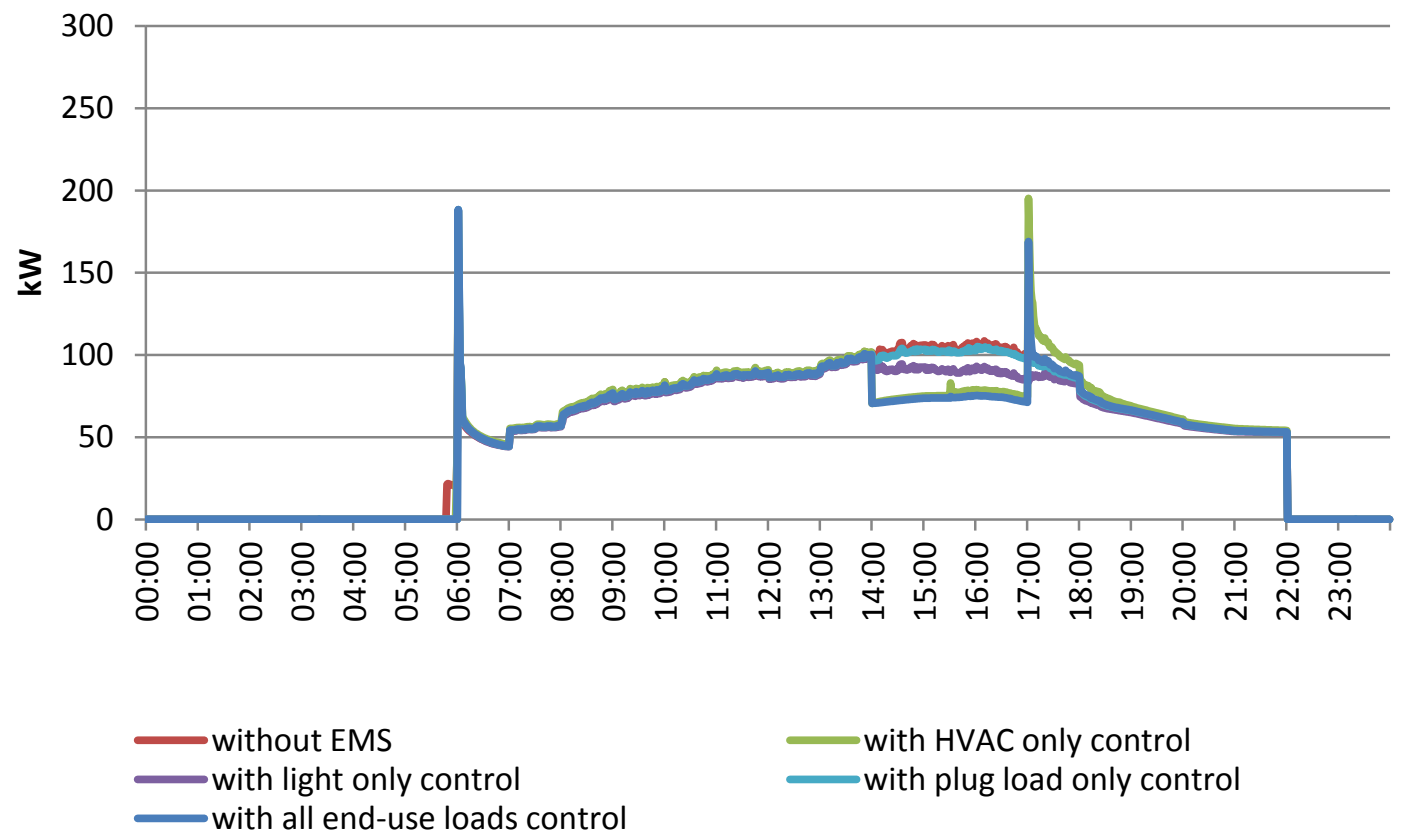

Fig.10 Simulated building's HVAC peak load with and without end-use load control by EMS for a summer day

Figures 9 and 10 show peak load savings achieved for the simulated building and its HVAC system with EMS respectively. By controlling HVAC, lights and plug loads in all zones using the proposed approach, building energy consumption and peak load can be reduced. From Figures 9 and 10 it is observed that without EMS the peak load occurs at around 4:10pm due to high outside temperatures and internal loads. The peak load values for the simulated building and HVAC without EMS are 224.68kW and $108.61 \mathrm{~kW}$ respectively. After implementing the proposed DR approach, the building's peak load at 4:10pm is reduced to 
$126.88 \mathrm{~kW}$, representing a $43.53 \%$ decrease from the original peak load. The HVAC peak load is reduced to $75.13 \mathrm{~kW}$, representing a $30.83 \%$ decrease from the original HVAC load.

From Figure 10 it is observed that the HVAC electric load has a spike when DR event ends. In case of all end-use loads control with EMS, if all zones' cooling set points are abruptly brought back to normal operation at the end of DR event - at 5pm instantly HVAC load increases from $71.21 \mathrm{~kW}$ to $168.96 \mathrm{~kW}$, representing an increase of $137.27 \%$. This exceeds the original HVAC peak load at 4:10pm without EMS by roughly $60.34 \mathrm{~kW}$. However, it is interesting to note that if only HVAC load is controlled (no lighting and plug load controls), the HVAC load increases from $74.73 \mathrm{~kW}$ to $195.14 \mathrm{~kW}$ at the end of a DR event. This represents a $161.13 \%$ increase. With all end-use loads control this restrike is less due to the decrease in cooling load by dimming selected lights and shutting down some plug loads during the DR event. Lighting and plug loads do not produce any demand restrike at the end of DR event. Authors in (Sehar et al., 2016) present strategies to reduce this demand restrike by extending DR duration or by slowly bringing back the cooling set points to their nominal values.

\subsection{DR potential of the simulated medium-sized office building}

Table 2 shows the peak load savings with EMS during the DR event. It is observed that light control achieves maximum peak load savings followed by cooling set point control. Interactive relationship between lighting/plug control and building thermal load can also be observed. Energy dissipated by lighting and plug loads within the building introduces internal heat gains which is a fraction of the building cooling load. By dimming selected lights and shutting down some plug loads during the DR event the associated heat gain reduces - leading to the decrease in cooling load and HVAC power consumption. Lighting and plug load controls reduce HVAC power consumption by $14.35 \%$ and $3.75 \%$ respectively.

Table.2 Peak load of simulated building and HVAC with and without EMS for a summer day

\begin{tabular}{|c|c|c|}
\hline & \multicolumn{2}{|c|}{$\begin{array}{c}\text { Peak load at 4:10pm }(\mathrm{kW}) \\
\text { (\% Savings) }\end{array}$} \\
\hline & Building & $108.61(0)$ \\
\hline Without EMS & $224.68(0)$ & $93.03(14.35)$ \\
\hline Lighting control only & $150.47(33.03)$ & $78.65(27.59)$ \\
\hline Cooling set points control only & $194.17(13.34)$ & $104.54(3.75)$ \\
\hline Plug load control only & $214.91(4.35)$ & $75.13(30.83)$ \\
\hline All end-use loads controls & $126.88(43.53)$ & \\
\hline
\end{tabular}

Table 3 shows the energy consumption for the entire summer day with and without EMS. Building energy consumption is influenced by weather conditions, internal loads and hours of operation. It is observed that lighting control alone achieves most savings followed by cooling set point control, as shutting down lights not only reduces energy consumption by lights but also the cooling load. As only few plug loads are being shut down during DR event, impact on simulated building and its HVAC load is 
not significant. Implementing control of all end-use loads reduces the simulated building and its HVAC load's energy consumptions by $9.57 \%$ and $7.47 \%$ respectively.

Table.3 Energy consumption of simulated building and HVAC with and without EMS for a summer day

\begin{tabular}{|c|c|c|c|c|}
\hline & \multicolumn{4}{|c|}{$\begin{array}{c}\text { Energy consumption (GJ) } \\
(\% \text { Savings })\end{array}$} \\
\hline & Building & Light & Plug loads & HVAC \\
\hline Without EMS & $10.45(0)$ & $3.42(0)$ & $1.88(0)$ & $4.55(0)$ \\
\hline Lighting control only & $9.58(8.32)$ & $2.79(18.42)$ & $1.88(0)$ & $4.31(5.27)$ \\
\hline Cooling set points control only & $10.26(1.82)$ & $3.42(0)$ & $1.88(0)$ & $4.36(4.18)$ \\
\hline Plug load control only & $10.37(0.76)$ & $3.42(0)$ & $1.85(1.60)$ & $4.50(1.10)$ \\
\hline All end-use loads controls & $9.45(9.57)$ & $2.79(18.42)$ & $1.85(1.60)$ & $4.21(7.47)$ \\
\hline
\end{tabular}

\section{Discussion}

Achieved results show that the integrated control for HVAC, lighting and plug loads developed in EnergyPlus EMS successfully lowers building's peak load at 4:10pm by $43.53 \%$. Moreover the overall energy consumption for the simulated day is also lowered due to the integrated control. The integrated control is able to meet occupant comfort requirements-thermal and lighting at all times during the DR event. Some key points are taken from the simulation results as follows:

Internal loads impact a zone's cooling load. Zones with higher internal loads, such as high plug load density, have increased cooling load hence require more air-conditioning to maintain thermal comfort. Zones with higher solar gain, which affects the building occupant thermal comfort as it includes the amount of heat transferred to the building, cannot have their space temperature cooling set points raised to high values for longer periods of time as they quickly get hot. If only cooling set points are adjusted during a DR event, demand rebound is high as the cooling set points are immediately lowered at the end of DR event when cooling load is high and HVAC systems uses extra energy to remove the heat gained during reduced service levels of DR event. However, implementing lighting and plug load controls together with HVAC control reduces building cooling load and hence the demand restrike associated with HVAC. Results also shows that for the simulated office building, lighting load control contributes the most to the building's peak load reduction, followed by HVAC and plug load control.

\section{Conclusions}

There is an increasing concern about grid reliability and growth towards energy efficiency. Smart buildings are an integral part of smart grid where buildings can change their electric usage by responding to DR signals during peak hours. This paper establishes a successful approach to lower a building's peak electrical demand through end-use load control which can also be adopted in other types and sizes of commercial buildings which in turn helps lower the grid's peak load. Utilities' needs for expensive generation or purchases to meet grid's peak load can be reduced by lowering building's demand. The specified approach can also be an integral part of a building's operation on a daily basis, as it meets comfort requirements, to achieve energy efficiency. 
The research offers an improved understanding of building's peak demand reduction potential as a result of performing DR to maximize building's economic benefits while maintaining occupant thermal and lighting needs. This translates to improving the grid's reliability and efficiency. A typical summer day has been analyzed in this paper to demonstrate the applicability of the proposed approach. Moreover the approach can be applied to other weather patterns, resulting in variation of peak reduction and energy savings potentials of a building throughout a year.

Additionally, dynamic plug load models of key office plug loads have been analyzed, developed and incorporated into EnergyPlus and used for building simulation purposes, thus improving the accuracy of simulation results. The optimal control of each zone's space temperature set points results in occupant satisfaction across the building. Space temperature set points cannot be much increased for zones with higher solar gains in order to maintain occupant thermal comfort. Lighting control, for zones with and without natural daylight, presented in this paper is able to closely maintain the illuminance levels at desired levels. Use of building energy simulation tool provides more accurate DR savings unlike other studies which estimate building's load profiles using baseline methods.

Overall, the knowledge gained through this research will help researchers develop new and improved controls for reducing building peak load. This work is an integral part of smart building research. Researchers can implement similar ideas for load control of a building in a microgrid and smart grid. The study at present does not include the integration of renewable generation and storage at customer side with demand responsive buildings to meet net-zero energy buildings requirements. Future work is to study optimal sizing of photovoltaic \& storage and their integrated automation with DR to meet grid's demand reduction target.

\section{Acknowledgement}

This material is based upon work supported by U.S. National Science Foundation under Grant\# ECCS-1232076 and Qatar Foundation Grant\# NPRP6-244-2-103.

\section{References}

Acker, B., Duarte, C., \& Wymelenberg, K. V. D. (2012). Office Space Plug Load Profiles and Energy Saving Interventions. Paper presented at the Proceedings of the 2012 ACEEE summer study on energy efficiency in buildings, Pacific Grove, CA.

Aduda, K. O., Labeodan, T., Zeiler, W., Boxem, G., \& Zhao, Y. (2016). Demand side flexibility: Potentials and building performance implications. Sustainable Cities and Society, 22, 146-163. doi: http://dx.doi.org/10.1016/j.scs.2016.02.011

Al-Mulla, A., \& ElSherbini, A. (2014). Demand management through centralized control system using power line communication for existing buildings. Energy Conversion and Management, 79, 477-486. doi: http://dx.doi.org/10.1016/j.enconman.2013.12.011

Al-Mulla, A., Maheshwari, G. P., Al-Nakib, D., ElSherbini, A., Alghimlas, F., Al-Taqi, H., \& Al-Hadban, Y. (2013). Enhancement of building operations: A successful approach towards national electrical demand management. Energy Conversion and Management, 76, 781-793. doi: http://dx.doi.org/10.1016/j.enconman.2013.07.080

Arnold, D., Sankur, M., \& Auslander, D. M. (2013). An architecture for enabling distributed plug load control for commercial building demand response. Innovative Smart Grid Technologies (ISGT), IEEE PES, 1-6.

Ashley, R., \& Reynolds, J. S. (1994). Overall and zonal energy end use in an energy conscious office building. Solar Energy, 52(1), 75-83. doi: http://dx.doi.org/10.1016/0038-092X(94)90083-E

ASHRAE. (2013a). Nonresidential Cooling and Heating Load Calculations ASHRAE Handbook Fundamentals.

ASHRAE. (2013b). Thermal Comfort ASHRAE Handbook of Fundamentals.

Begemann, S. H. A., Beld, G. J., \& Tenner, A. D. (1997). Daylight, artificial light and people in an office environment, overview of visual and biological responses. International Journal of Industrial Ergonomics, 231-239. 
BigLadderSoftware. (2015). Input Output Reference - EnergyPlus 8.3. 2015, from http://bigladdersoftware.com/epx/docs/83/input-output-reference/

Boyce, P. R., Veitch, J. A., Newsham, G. R., Jones, C. C., Heerwagen, J. M., Myer, M., \& Hunter, C. M. (2006). Occupant use of switching and dimming controls in offices. Lighting Research and Technology, 38(4), 358-378.

Carlucci, S., Causone, F., Rosa, F. D., \& Pagliano, L. (2015). A review of indices for assessing visual comfort with a view to their use in optimization processes to support building integrated design. Renewable and Sustainable Energy Reviews, 47, 1016-1033. doi: http://dx.doi.org/10.1016/j.rser.2015.03.062

Chantrasrisalai, C., \& Fisher, D. E. (2007). Lighting Heat Gain Parameters: Experimental Results (RP-1282). HVAC\&R Research, 13(2).

CPSEnergy. (2016). Commercial Demand Response. 2016, from http://www.cpsenergysavers.com/commercial/startsaving/demand-response

Crawley, D. B., Lawrie, L. K., Winkelmann, F. C., Buhl, W. F., Huang, Y. J., Pedersen, C. O., . . Glazer, J. (2001). EnergyPlus: creating a new-generation building energy simulation program. Energy and Buildings, 33(4), 319-331. doi: http://dx.doi.org/10.1016/S0378-7788(00)00114-6

Cui, C., Wu, T., Hu, M., Weir, J., \& Li, X. (2016). Short-term building energy model recommendation system: A meta-learning approach. Applied Energy, 172, 251-263. doi: http://dx.doi.org/10.1016/j.apenergy.2016.03.112

Derrible, S., \& Reeder, M. (2015). The cost of over-cooling commercial buildings in the United States. Energy and Buildings, 108, 304-306.

DiLaura, D. L., Houser, K. W., Mistrick, R. G., \& Steffy, G. R. (2000). IESNA Lighting Handbook: Reference and Application (9 ed.). New York: Illuminating Engineering Society of North America (IESNA).

DiLaura, D. L., Houser, K. W., Mistrick, R. G., \& Steffy, G. R. (2011a). Light Sources: Application Considerations IESNA The Lighting Handbook: Reference and Application (10 ed.): Illuminating Engineering Society of North America.

DiLaura, D. L., Houser, K. W., Mistrick, R. G., \& Steffy, G. R. (2011b). Luminaires : Forms and Optics The Lighting Handbook : Reference and Application (10 ed.): Illuminating Engineering Society of North America (IESNA).

DOE. (2011a). Commercial Reference Buildings. 2015, from http://energy.gov/eere/buildings/commercial-reference-buildings

DOE. (2011b). Weather Data. 2015, from https://energyplus.net/weather

DOE. (2013). Application Guide for EMS Energy Management System User Guide: U.S. Department of Energy.

Dubois, M.-C., \& Blomsterberg, Å. (2011). Energy saving potential and strategies for electric lighting in future North European, low energy office buildings: A literature review. Energy and Buildings, 43(10), 2572-2582. doi: http://dx.doi.org/10.1016/j.enbuild.2011.07.001

EIA. (2008). Commercial Buildings Energy Consumption Survey 2003, Table E3A., from http://www.eia.gov/totalenergy/data/annual/showtext.cfm?t=ptb0211

EIA. (2010). Office

Buildings.

from https://www.eia.gov/consumption/commercial/data/archive/cbecs/cbecs2003/officereport/office2.html

EIA. (2012). Commercial Buildings Energy Consumption (CBECS) Survey Data. from http://www.eia.gov/consumption/commercial/data/2012/

FERC. (2011). 2010 Assessment of Demand Response and Advanced Metering: Federal Energy Regulatory Commission.

Galasiu, A., Atif, M. R., \& MacDonald, R. A. (2004). Impact of window blinds on daylight-linked dimming and automatic on/off lighting controls. Solar Energy, 76(5), 523-544.

Galasiu, A., \& Veitch, J. A. (2007). Occupant preferences and satisfaction with the luminous environment and control systems in daylight offices: a literature review. Energy and Buildings, 38(7), 728-742.

Gandhi, P., \& Brager, G. S. (2016). Commercial office plug load energy consumption trends and the role of occupant behavior. Energy and Buildings, 125, 1-8. doi: http://dx.doi.org/10.1016/j.enbuild.2016.04.057

Gelazanskas, L., \& Gamage, K. A. A. (2014). Demand side management in smart grid: A review and proposals for future direction. Sustainable Cities and Society, 11, 22-30. doi: http://dx.doi.org/10.1016/j.scs.2013.11.001

Gentile, N., Laike, T., \& Dubois, M.-C. (2014). Lighting control systems in peripheral offices rooms at high latitude: measurements of electricity savings and users preferences. Energy Procedia, 57, 1987-1996.

Gils, H. C. (2014). Assessment of the theoretical demand response potential in Europe. Energy, 67, 1-18. doi: http://dx.doi.org/10.1016/j.energy.2014.02.019

Goldstein, N., \& Bloom, E. (2014). Energy Management for Small and Medium Buildings Navigant Research.

Hosni, M. H., Jones, B. W., \& Xu, H. (1999). Measurement of Heat Gain and Radiant/Convective Split from Equipment in Buildings: ASHRAE.

Kamilaris, A., Kalluri, B., Kondepudi, S., \& Kwok Wai, T. (2014). A literature survey on measuring energy usage for miscellaneous electric loads in offices and commercial buildings. Renewable and Sustainable Energy Reviews, 34(0), 536-550. doi: http://dx.doi.org/10.1016/j.rser.2014.03.037

Kamilaris, A., Kalluri, B., Kondepudi, S., \& Tham, K. W. (2014). A literature survey on measuring energy usage for miscellaneous electric loads in offices and commercial buildings. Renewable and Sustainable Energy Reviews, 34, 536550.

Kaneda, D., Jacobson, B., \& Rumsey, P. (2010). Plug Load Reduction: The Next Big Hurdle for Net Zero Energy Building Design. ACEEE Summer Study on Energy Efficient Buildings, 9, 120-130. 
Karaguzel, O. T., \& Lam, K. P. (2011, 11-14 Dec. 2011). Development of whole-building energy performance models as benchmarks for retrofit projects. Paper presented at the Proceedings of the 2011 Winter Simulation Conference (WSC).

Katipamula, S., Piette, M., Kuruganti, T., Underhill, R. M., Granderson, J., Goddard, J. K., . . Lanzisera, L. (2012). Small- and Medium-Sized Commercial Building Monitoring and Controls Needs: A Scoping Study: PNNL-22169.

Kawamoto, K., Koomey, J. G., Bruce Nordman, Brown, R. E., Piette, M. A., Ting, M., \& Meier, A. K. (2001). Electricity Used by Office Equipment and Network Equipment in the U.S.:Detailed Report and Appendices: Lawrence Berkeley National Laboratory (LBNL).

Kawamoto, K., Koomey, J. G., Nordman, B., Brown, R. E., Piette, M. A., Ting, M., \& Meier, A. K. (2002). Electricity used by office equipment and network equipment in the US. Energy, 27(3), 255-269. doi: http://dx.doi.org/10.1016/S03605442(01)00084-6

Kawamoto, K., Shimoda, Y., \& Mizuno, M. (2004). Energy Saving Potential of Office Equipment Power Management. Energy and Buildings, 36(9), 915-923.

Kreuder, L., \& Spataru, C. (2015). Assessing demand response with heat pumps for efficient grid operation in smart grids. Sustainable Cities and Society, 19, 136-143. doi: http://dx.doi.org/10.1016/j.scs.2015.07.011

Kwong, Q. J., Goh, S. H., Adam, N. M., \& Raghavan, V. R. (2014). A Study on Energy Efficiency Improvement Opportunities for Plug Loads in Buildings in the Equatorial Region. Energy Procedia, 56(0), 621-633. doi: http://dx.doi.org/10.1016/j.egypro.2014.07.201

Li, X., Wen, J., \& Bai, E.-W. (2016). Developing a whole building cooling energy forecasting model for on-line operation optimization using proactive system identification. Applied Energy, 164, 69-88. doi: http://dx.doi.org/10.1016/j.apenergy.2015.12.002

LightSearch. (2014). Light Guide: Useful Formulas. from http://www.lightsearch.com/resources/lightguides/formulas.html

Lobato, C., Sheppy, M., Brackney, L., Pless, S., \& Torcellini, P. (2012). Selecting a Control Strategy for Plug and Process Loads National Renewable Energy Laboratory (NREL).

Love, J. A. (1998). Manual switching patterns in private offices. Lighting Research and Technology, 30(1), 45-50.

MACEBUR. (1998). Energy-Efficient Office Technologies : the 1 Watt / 1Volt-Ampere Challenge

Melki, S., \& Hayek, M. (2009). Building simulation tools and their role in improving existing building designs. Paper presented at the International Conference on Advances in Computational Tools for Engineering Applications (ACTEA), Zouk Mosbeh.

Metzger, I., Cutler, D., \& Sheppy, M. (2012). Plug-Load Control and Behavioral Change Research in GSA Office Buildings: National Renewable Energy Laboratory (NREL).

Meyer, \& Schaltegger. (1999). Determination of energy consumption of consumer electronics devices, Office equipment and machines in the Switzerland: Swiss Federal Office of Energy.

Moore, T., Carter, D. J., \& Slater, A. I. (2002). User attitude toward occupant controlled office lighting. Lighting Research and Technology, 34(3), 207-219.

Moore, T., Carter, D. J., \& Slater, A. I. (2003). Long-term patterns of use of occupant controlled office lighting. Lighting Research and Technology, 35(1), 43-57.

Motegi, N., Piette, M. A., Watson, D., Kiliccote, S., \& Xu, P. (2007). Introduction to Commercial Building Control Strategies and Techniques for Demand Response: Lawrence Berkeley National Laboratory (LBNL)

Mungwititkul, W., \& Mohanty, B. (1997). Energy efficiency of office equipment in commercial buildings: The case of Thailand. Energy, 22(7), 673-680.

Newsham, G. R., Aries, M. B. C., Mancini, S., \& Faye, G. (2008). Individual control of electric lighting in a daylit space. Lighting Research and Technology, 40(1), 25-41.

Nordman, B., Meier, A., \& Piette, M. A. (2000). PC and monitor night status: Power management enabling and manual turn-off. Paper presented at the Proceedings ACEEE Summer Study on Energy Efficiency in Buildings, Pacific Grove, CA (US).

Page, J., Kiliccote, S., Dudley, J. H., \& Piette, M. A. (2011). Automated Demand Response Technology Demonstration for Small and Medium Commercial Buildings Lawrence Berkeley National Laboratory (LBNL).

Park, S., Ryu, S., Choi, Y., \& Kim, H. (2014). A Framework for Baseline Load Estimation in Demand Response: Data Mining Approach. Paper presented at the IEEE International Conference on Smart Grid Communications.

Perez, R., Ineichen, P., Seals, R., Michalsky, J., \& Stewart, R. (1990). Modeling daylight availability and irradiance components from direct and global irradiance. Solar Energy, 44(5), 271-289. doi: http://dx.doi.org/10.1016/0038-092X(90)90055-H

PJM. (2016). PJM Demand Response. 2016, from http://www.pjm.com/markets-and-operations/demand-response.aspx

Plat, G., Ward, J. K., \& Wall, J. (2011). Optimal Supervisory HVAC Control: Experiences in Australia. HVAC\&R Research, $17(3), 297-308$.

Poll, S., \& Teubert, C. (2012). Pilot Study of a Plug Load Management System: Preparing for Sustainability Base. Paper presented at the IEEE Green Technologies Conference, Tulsa, OK.

Ramos, G., \& Ghisi, E. (2010). Analysis of daylight calculated using the EnergyPlus programme. Renewable and Sustainable Energy Reviews, 14(7), 1948-1958. doi: http://dx.doi.org/10.1016/j.rser.2010.03.040

RapidTables. (2015). How to convert watts to lux. 2015, from http://www.rapidtables.com/calc/light/how-watt-to-lux.htm

Ritter, J., \& Hugghins, J. (2000). Vending Machine Energy Consumption and VendingMiser Evaluation: Energy Systems Laboratory Texas A\&M University System. 
Roth, K. W., Goldstein, F., \& Kleinman, J. (2002). Energy Consumption by Office and Telecommunications Equipment in Commercial Buildings Volume I: Energy Consumption Baseline: Arthur D. Little, Inc.

Royapoor, M., \& Roskilly, T. (2015). Building Model Calibration Using Energy and Environmental Data. Energy and Buildings, 94, 109-120. doi: http://dx.doi.org/10.1016/j.enbuild.2015.02.050

Sehar, F., Pipattanasomporn, M., \& Rahman, S. (2016). A peak-load reduction computing tool sensitive to commercial building environmental preferences. Applied Energy, 161, 279-289.

Shen, E., Hu, J., \& Patel, M. (2014). Energy and visual comfort analysis of lighting and daylight control strategies. Building and Environment, 78, 155-170.

Smith, A. M., \& Brown, M. A. (2015). Demand response: A carbon-neutral resource? Energy, 85, 10-22. doi: http://dx.doi.org/10.1016/j.energy.2015.02.067

Thornton, B., Wang, W., Lane, M., Rosenberg, M., \& Liu, B. (2009). Technical Support Document: 50\% Energy Savings Design Technology Packages for Medium Office Buildings: Pacific Northwest National Laboratory (PNNL).

Toftum, J., Andersen, R. V., \& Jensen, K. L. (2009). Occupant performance and building energy consumption with different philosophies of determining acceptable thermal conditions. Building and Environment, 44(10), 2009-2016.

Turner, S. C. (2011). What's New in ASHRAE's Standard on Comfort. ASHRAE.

Tzivanidis, C., Antonopoulos, K. A., \& Gioti, F. (2011). Numerical simulation of cooling energy consumption in connection with thermostat operation mode and comfort requirements for the Athens buildings. Applied Energy, 88, $2871-2884$.

Veitch, J. A., \& Newsham, G. R. (2002). Preferred luminous conditions in open-plan offices: research and practice recommendations. Lighting Research and Technology, 32, 199-212.

VirginiaTech. (2016). Introducing BEMOSS ${ }^{\mathrm{TM}}$ An open source platform for building energy management. from http://www.bemoss.org/

Wang, J., Biviji, M. A., \& Wang, W. M. (2011). Lessons learned from smart grid enabled pricing programs. Paper presented at the Power and Energy Conference (PECI), http://ieeexplore.ieee.org/stamp/stamp.jsp?tp=\&arnumber=5740488\&isnumber $=5740475$

Watson, D., Kiliccote, S., Motegi, N., \& Piette, M. (2006). Strategies for demand response in commercial buildings. Proceedings of the 2006 ACEEE Summer Study on Energy Efficiency in Buildings.

Webber, C. A., Roberson, J. A., McWhinney, M. C., Brown, R. E., Pinckard, M. J., \& Busch, J. F. (2006). After-hours power status of office equipment in the USA. Energy, 31(14), 2823-2838.

Weng, T., Balaji, B., Dutta, S., Gupta, R., \& Agarwal, Y. (2011). Managing Plug-Loads for Demand Response within Buildings. Paper presented at the Proceedings of the ACM Workshop on Embedded Sensing Systems For Energy-Efficiency, Seattle.

Wilkins, C., \& Hosni, M. H. (2000). Heat Gain From Office Equipment. ASHRAE, 33-43.

Yan, C., Xue, X., Wang, S., \& Cui, B. (2015). A novel air-conditioning system for proactive power demand response to smart grid. Energy Conversion and Management, 102, 239-246. doi: http://dx.doi.org/10.1016/j.enconman.2014.09.072

Yanga, L., Yana, H., \& Lam, J. C. (2014). Thermal comfort and building energy consumption implications - A review. Applied Energy, 115, 164-173. 